\title{
A Role for Apolipoprotein E, Apolipoprotein A-I, and Low Density Lipoprotein Receptors in Cholesterol Transport during Regeneration and Remyelination of the Rat Sciatic Nerve
}

\author{
Janet K. Boyles, ${ }^{\star \ddagger}$ Cindy D. Zoellner, ${ }^{\star}$ Linda J. Anderson, ${ }^{\star}$ Lucia M. Kosik, ${ }^{\star}$ Robert E. Pitas, ${ }^{\star \ddagger}$ Karl H. Weisgraber, ${ }^{\star \star}$ \\ David Y. Hui, " Robert W. Mahley, ${ }^{\star \$}$ Peter J. Gebicke-Haerter," Michael J. Ignatius," and Eric M. Shooter" \\ ${ }^{*}$ Gladstone Foundation Laboratories for Cardiovascular Disease, Cardiovascular Research Institute, Departments of ${ }^{\ddagger}$ Pathology and \\ ${ }^{\S}$ Medicine, University of California, San Francisco, California 94140-0608; and "Department of Neurobiology, Stanford University \\ School of Medicine, Stanford, California 94305
}

\begin{abstract}
Recent work has demonstrated that apo E secretion and accumulation increase in the regenerating peripheral nerve. The fact that apoE, in conjunction with apoA-I and LDL receptors, participates in a well-established lipid transfer system raised the possibility that apoE is also involved in lipid transport in the injured nerve. In the present study of the crushed rat sciatic nerve, a combination of techniques was used to trace the cellular associations of apoE, apoA-I, and the $\mathrm{LDL}$ receptor during nerve repair and to determine the distribution of lipid at each stage. After a crush injury, as axons died and Schwann cells reabsorbed myelin, resident and monocyte-derived macrophages produced large quantities of apoE distal to the injury site. As axons regenerated in the first week, their tips contained a high concentration of $L D L$ receptors. After axon regeneration, apoE and apoA-I began to accumulate distal to the injury site and macrophages became increasingly cholesterol-loaded. As remyelination began in the second and third weeks after injury, Schwann cells exhausted their cholesterol stores, then displayed increased LDL receptors. Depletion of macrophage cholesterol stores followed over the next several weeks. During this stage of regeneration, apoE and apoA-I were present in the extracellular matrix as components of cholesterol-rich lipoproteins. Our results demonstrate that the regenerating peripheral nerve possesses the components of a cholesterol transfer mechanism, and the sequence of events suggests that this mechanism supplies the cholesterol required for rapid membrane biogenesis during axon regeneration and remyelination.
\end{abstract}

\section{Introduction}

After a denervating crush injury to the sciatic nerve, several proteins are induced in the distal, but not the proximal, seg-

Dr. Hui's present address is Department of Pathology and Laboratory Medicine, University of Cincinnati College of Medicine, 231 Bethesda Avenue (ML 529), Cincinnati, Ohio 45267. Dr. Gebicke-Haerter's present address is Pharmakologisches Institut, Albert-Ludwigs Universität, Hermann-Heyder Strasse 5, D-7800 Freiburg i. Br., Federal Republic of Germany. Dr. Ignatius's present address is Department of Physiology, University of California, San Francisco, CA 94143.

Address reprint requests to Dr. Janet K. Boyles, Gladstone Foundation Laboratories, P.O. Box 40608, San Francisco, CA 94140-0608.

Received for publication 2 October 1987 and in revised form 30 September 1988 .

J. Clin. Invest.

(c) The American Society for Clinical Investigation, Inc.

0021-9738/89/03/1015/17 \$2.00

Volume 83, March 1989, 1015-1031 ment of the injured nerve (1). One protein in particular, with $37,000 \mathrm{~mol} w \mathrm{wt}$ and an acidic isoelectric point, displays a several hundredfold increase in synthesis and secretion (2). The protein has recently been identified as a sialylated form of the plasma protein apoE $(3,4)$. The identification was based on a partial amino acid sequence of the protein, on its amino acid composition, and on its immunologic homology to authentic plasma-derived apoE.

In regenerating peripheral nerves, such as the sciatic nerve of the rat and rabbit, not only is the production of apoE dramatically increased, but the apoE also accumulates $(2,5)$. The production and accumulation of apoE decline after regeneration is complete $(2,5)$. Apolipoprotein $\mathrm{E}$ production also increases after injury to nonregenerating central nervous system fiber tracts, such as the rat optic nerve and spinal cord. In the central nervous system, however, apoE does not accumulate and the secretion of apoE remains high (2). Similarly, the production of apoE remains high in the distal segment of peripheral nerves in which regeneration has been prevented by cutting the nerve and tying off its proximal stump (1). Increased production of apoE has also been observed in the maturing sciatic nerve of the newborn rat $(1,5)$. These observations suggest that apoE is secreted by cells of the nerve and plays a central role in axon regeneration, de novo axon growth, and nerve maturation (1-5).

Apolipoprotein $\mathrm{E}$ has been intensively studied in nonnervous tissue as one of several apolipoproteins that direct lipid metabolism through their ability to promote the formation of lipoprotein particles and to interact with specific cellular receptors (for review, see references 6 and 7). Because it facilitates cholesterol movement both into and out of cells, apoE has been the focus of particular attention. Apolipoprotein Econtaining lipoproteins and LDL, which contain apoB, bind to the same cell-surface receptor, the LDL receptor. This receptor is displayed by cells requiring cholesterol and mediates the internalization and degradation of these lipoproteins (7). High density lipoproteins (HDL), lipoproteins rich in apoA-I, can extract cholesterol from cells loaded with excess cholesterol (8, 9). Apolipoprotein $E$ increases the efficiency of cholesterol removal by binding to the HDL particles, greatly augmenting their capacity to accumulate cholesteryl esters $(10,11)$. Because HDL particles acquire both cholesterol and apoE, the apoE on their surfaces allows them to be recognized by the LDL receptor displayed by extrahepatic cells requiring cholesterol and by parenchymal cells of the liver.

After a denervating crush injury, large amounts of lipid are released from degenerating axon membrane and myelin. Much of the cholesterol from these membranes is stored by cells in the nerve and reused during regeneration (12-14). During nerve degeneration and regeneration, apolipoproteins, 
such as apoE and apoA-I, and the LDL receptor could play a role in the requisite cholesterol transfers. The results of the current study suggest that they do.

\section{Methods}

Sprague-Dawley rats (250-450 g) of both sexes were used. Fine forceps were used to crush sciatic nerves where they emerged from the sciatic notch, as described in studies of apoE production in injured nerve $(1,2$, 5). Regions of the injured sciatic nerve 5-15 mm distal to the crush site were studied at $1,2,3,4,5,7,8,10,14,21,28,42$ (6 wk), 56 (8 wk), and $105 \mathrm{~d}(15 \mathrm{wk})$ after the trauma. An equivalent region of normal nerve was studied. Sections of normal and injured nerve were cut and incubated in the appropriate rabbit hyperimmune serum to detect the following antigens: apoE, the LDL receptor, apoA-I (the major protein of HDL), IgG (a plasma protein marker), and lysozyme (a granulocyte and macrophage marker). Monoclonal antibodies to rat macrophages and monocytes, as well as to neurofilaments, were also used. Preimmune sera were used as controls for apoE, apoA-I, and LDL receptor antisera. Sections incubated with the preimmune sera were negative. Under the conditions used in this study, the tissues showed no endogenous peroxidase reaction or binding of secondary antibodies. Electron microscopy and morphometry were used to correlate the results of the immunocytochemical study with events in the regenerating nerve segment.

Light-microscopic immunocytochemistry. Our initial work with apoE showed that there was a loss of antigenicity when the tissues were dehydrated. Therefore, cryostat sections of fixed and cryoprotected tissue were used. The same procedure was used for all antigens so that they could be detected on serial sections of the same tissue. Perfusion fixation of nerve tissue with formaldehyde and processing of cryostat sections for light-microscopic immunocytochemistry were performed essentially as described (15). Cryostat sections were cut and dried onto gelatin-coated slides. Nonspecific binding was blocked by incubation for $30 \mathrm{~min}$ in half-strength PBS containing $0.1 \%$ dry nonfat milk, $2 \%$ serum (from the same species as the second antibody), $0.15 \mathrm{M}$ ammonium acetate, and $0.1 \%$ Triton $\mathrm{X}-100$. The sections were incubated overnight in various dilutions of immune sera $(1: 5,000$ to $1: 80,000)$ or affinity-purified antibody in PBS containing $0.1 \%$ nonfat milk, $2 \%$ serum, $15 \mathrm{mM}$ ammonium acetate, and $0.15 \%$ Triton X-100. Sections were washed in the same buffer, and the primary antibody was detected using a biotinylated second antibody followed by an avidin-biotin peroxidase complex (Vector Laboratories, Inc., Burlingame, CA) in the same buffer but without serum. A black peroxidase reaction product was produced by incubating the slides for $2 \mathrm{~min}$ in a buffer of $0.1 \mathrm{M}$ monobasic sodium phosphate and ammonia, $\mathrm{pH} 6.8$, that contained $0.06 \%$ nickel chloride, $0.2 \mathrm{mg} / \mathrm{ml}$ of $3,3^{\prime}$-diaminobenzidine, and $0.03 \%$ $\mathrm{H}_{2} \mathrm{O}_{2}$. No endogenous peroxidase reaction was detected on slides of this tissue processed in this manner. Methyl green ( $2 \%$ in water) was used to stain cell nuclei.

Relative concentrations of individual antigens were determined at various time points or within various regions of the tissue by serially diluting the primary antibody and comparing the resulting intensities of the peroxidase reaction product. Since peroxidase reaction product intensity depends on the concentration of the antigen/antibody complex, a decrease in either the antigen concentration in the tissue or the antibody concentration in the first incubation step results in less product. Comparisons of the intensity of peroxidase reaction in different nerves and tissues assume equal access of the antibody to the antigen and equal sensitivity of the antigen to fixation.

For simultaneous labeling of two antigens, fluorescence microscopy was used. Rabbit antisera and ascites fluids were used as described (16). Rabbit anti-rat apoE was used at 1:1,000 to 1:4,000, mouse anti-macrophage ascites (MCA 341 and MCA 342 mixed, Serotec Ltd., Oxford, England) at 1:8,000, and mouse anti-160-kD neurofilament ascites (Amersham/Searle, Arlington Heights, IL) at 1:8,000.

Electron-microscopic immunocytochemistry. To detect apolipo- proteins by electron microscopy, a preembedding technique similar to ones previously described (15) was used. Thick $(20-\mu \mathrm{m})$ frozen sections of the same tissue as used for light-microscopic work were incubated for $36 \mathrm{~h}$ in a 1:750 dilution of the rat apoE-specific or apoA-I-specific rabbit serum without detergent. After a 6-h wash, the sections were transferred to a 1:150 dilution of peroxidase-coupled $\mathrm{F}\left(\mathrm{ab}^{\prime}\right)_{2}$ (Zymed Laboratories, San Francisco, CA) specific for rabbit IgG. After a 6-h incubation and 3-h wash, the sections were fixed by adding $10 \%$ glutaraldehyde to the wash solution to make a final concentration of $1 \%$. After washing, they were allowed to react for $15 \mathrm{~min}$ in a $2 \mathrm{mg} / \mathrm{ml}$ solution of 3,3'-diaminobenzidine in a buffer of $0.1 \mathrm{M}$ monobasic sodium phosphate and ammonia, $\mathrm{pH}$ 7-7.5. After a rinse, the sections were fixed for $2 \mathrm{~h}$ in $2 \%$ osmium tetroxide and $2 \%$ potassium ferricyanide in buffer, rinsed in water, dehydrated with acetone, and embedded. No stain was used on the sections.

Electron microscopy. Tissue from perfusion-fixed animals was examined by thin-section electron microscopy. The tissue was fixed for from $1 \mathrm{~h}$ to overnight in $2 \%$ glutaraldehyde, $2 \%$ formaldehyde (freshly prepared from paraformaldehyde) in $0.08 \mathrm{M}$ cacodylate buffer ( $\mathrm{pH}$ 7.2), or $3 \%$ glutaraldehyde in the same buffer, followed by a $2-\mathrm{h}$ fixation in a solution of $2 \%$ osmium tetroxide and $2 \%$ potassium ferricyanide in Palade's buffer. En bloc staining overnight with $2 \%$ uranyl acetate in water completed the fixation. A prolonged osmication step (which includes the ferricyanide ion, an osmium ligand) and en bloc uranyl acetate staining enhanced lipoprotein delineation (17-19). Both procedures help to stain phospholipid bilayers in cells and even enhance the staining of the phospholipid monolayer at the lipoprotein surface. Particles as small as LDL or as large as VLDL are readily identified after this fixation, whereas they are extremely difficult to identify after conventional fixation. For most nerves it was necessary to add a delipidation step after the acetone dehydration and before the embedding procedure. Delipidation was accomplished by agitating the tissue blocks in chloroform:methanol (2:1) for $30 \mathrm{~min}$ to $2 \mathrm{~h}$.

Negative staining was done using $1 \%$ phosphotungstate and $0.1 \%$ sucrose. Sample was applied to carbon films formed on mica, and excess sample was washed off with the staining solution.

Morphometric analysis. Standard procedures for obtaining percent volume were used (20). Single sections of a nerve from two animals for each time point were mounted on 300 -mesh grids, and micrographs were taken at 4,000 magnification from the upper left-hand corner of each grid square. The resulting $\approx 40-100$ micrographs per nerve were then enlarged to 10,000 magnification and evaluated using a dot matrix. For cells, axons, and Schwann cell lysosomes, a 4-cm grid was used; for lysosomes in other cells, for lipid droplets, and for myelin, a $2-\mathrm{cm}$ grid was used. Because the extent of matrix or space between cells was highly variable, the percent volume occupied by Schwann cells, nerve axons, and macrophages or neurolemmal fibroblasts was adjusted to equal $100 \%$ of total nerve volume; thus, the variable extracellular space was excluded from all calculations. Lysosomes and endosomes were defined as membrane-enclosed compartments that were not recognizable as other cellular organelles. The vast majority of these compartments contained lipid debris of various kinds.

Antisera. Two commercial sera were used: rabbit anti-human lysozyme (Dako Corp., Santa Barbara, CA) and rabbit anti-rat IgG (Zymed). Rat apoE and rat apoA-I were isolated as described $(21,22)$, with a final purification step using isoelectric focusing on a preparative Immobiline gel (23). Bovine LDL receptors were purified from bovine adrenal membranes by immunoaffinity chromatography on an IgG-C7-Sepharose column as described (24). The bound fraction was eluted by ammonium hydroxide (24) and used without further purification.

The antibodies were raised in specific pathogen-free New Zealand White rabbits $(2.5-3 \mathrm{~kg})$, which had been screened for nonspecific binding of their serum to the tissues before immunization. To analyze antibody specificity, we used Western blots (25) of rat plasma (the source of apoE and apoA-I), bovine adrenal membranes (the source of LDL receptors), or rat liver membranes from normal or estradioltreated animals. Rat serum was reduced, but the bovine adrenal mem- 
branes (24), normal rat liver membranes $(26,27)$, and liver membranes from $17 \alpha$-ethinylestradiol-treated animals $(26,27)$ were used without reduction to prevent loss of LDL receptor antigenicity. The samples were electrophoresed on SDS-polyacrylamide slab gels (28) and transferred onto nitrocellulose paper, and proteins were identified immunologically as described (25) or by using the same peroxidase procedure as for tissue sections.

Both anti-rat apoE and anti-rat apoA-I hyperimmune sera were specific for their respective antigens when tested for reaction with the proteins of rat plasma (Fig. 1, $A$ and $B$ ). The LDL receptor-specific antiserum cross-reacted with rat IgG and a rat serum protein (probably as a result of contaminant mouse proteins eluted from the IgG-C7Sepharose affinity column). These cross-reacting antibodies were removed by absorption for $2 \mathrm{~d}$ with a 10 -fold excess of whole rat serum and $1 \mathrm{mg}$ of mouse $\mathrm{IgG} / \mathrm{ml}$. The absorbed anti-bovine LDL receptor hyperimmune serum identified a band at $130 \mathrm{kD}$ (the molecular weight of the receptor $[24,29])$ when tested for reaction with the proteins of bovine adrenal membranes (Fig. $1 C$ ). The serum also identified a protein of similar molecular weight in normal rat liver membranes; this protein was increased in the membranes of $17 \alpha$-ethinylestradiol-treated rats. The LDL receptor is known to be increased in the latter membranes $(26,27)$. A second band, of twice the molecular weight of the receptor, appears to be a dimer of the receptor, as shown by ligand blotting (29). Canine apoE-rich $\mathrm{HDL}_{\mathrm{c}}$ (lipoproteins isolated from the plasma of cholesterol-fed animals [30]) labeled with ${ }^{125} \mathrm{I}$ (and incubated at $1 \mu \mathrm{g} / \mathrm{ml}$ of protein for $1 \mathrm{~h}$ with nitrocellulose blots of gels of these membranes) bound to both bands (Fig. 1 D).

A small quantity of affinity-purified LDL receptor antibody was produced by immunoabsorption to receptor electroeluted (31) from nonreduced SDS-polyacrylamide gels. $20 \mu \mathrm{g}$ of the receptor was absorbed onto $10 \mathrm{~cm}^{2}$ of nitrocellulose paper; residual protein binding was then blocked in milk, and the paper was used to absorb specific antibodies from $200 \mu \mathrm{l}$ of whole serum overnight. After washing, the bound antibodies were eluted with $100 \mathrm{mM} \mathrm{Na}$ citrate (pH 2.8), dialyzed, mixed 1:1 with glycerol, and frozen. At a dilution equivalent to 1:150 of the original serum, the eluted antibodies were equivalent in reactivity to whole serum used at 1:2,000. These antibodies were used only to confirm the specificity of the sera in the immunocytochemical study of tissue sections. No differences were noted in receptor localization using either the absorbed serum or the affinity-purified antibodies.

Isolation of lipoproteins. The sciatic nerves from normal rats and rats injured 4 wk earlier were harvested after all the blood had been removed by perfusion to ensure the absence of blood lipoproteins. The nerves were immediately chopped into a buffer containing protease inhibitors but no antioxidants (32). Lipoproteins were extracted from 10-20 nerves incubated in $15-30 \mathrm{ml}$ of the buffer at $4^{\circ} \mathrm{C}$ for $2-16 \mathrm{~h}$. The density of the extract was raised to $1.21 \mathrm{~g} / \mathrm{ml}$ by adding $\mathrm{KBr}$, and the extract was centrifuged in an SW41 rotor (Beckman Instruments,

\section{Anti-Apo-E Anti-Apo-A-I Anti-LDL Receptor}

\section{Apo-E HDL}

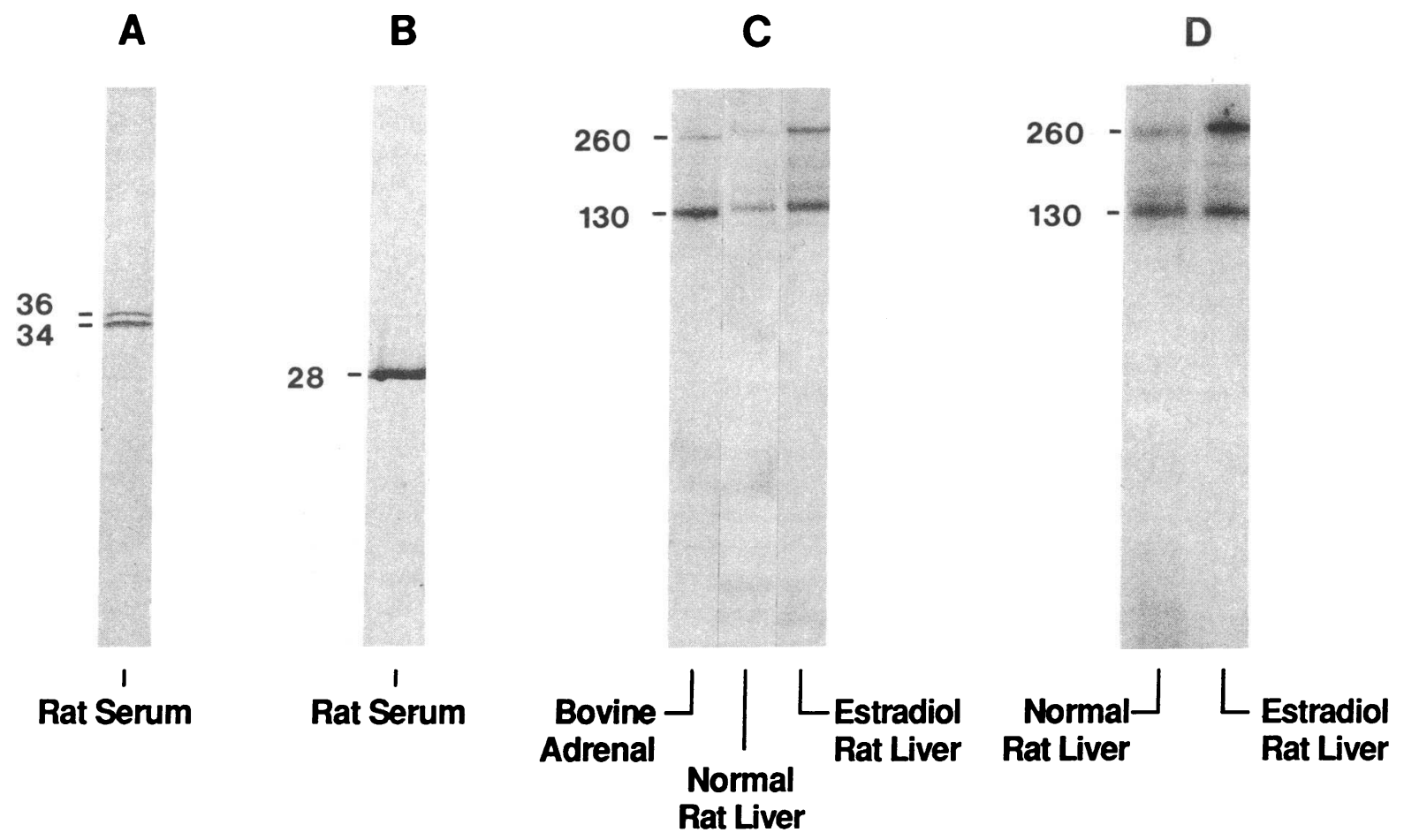

Figure 1. Characterization of the apoE, apoA-I, and LDL receptor antisera used in this study. $(A)$ Blot of a reduced $11 \%$ SDS-polyacrylamide gel of rat serum incubated in anti-apoE serum. Both nonsialylated apoE (mol wt 34,000) and a smaller quantity of the monosialylated form (mol wt 36,000) are detected. Peroxidase reaction product identifies the bound rabbit antibodies on this blot. $(B)$ Blot of a reduced $11 \%$ SDSpolyacrylamide gel of rat serum incubated in anti-apoA-I serum. Only apoA-I is identified. Peroxidase reaction product identifies bound rabbit antibodies on this blot. $(C)$ Autoradiogram of a blot of a nonreduced 7\% SDS-polyacrylamide gel on which equal quantities of bovine adrenal membranes, normal rat liver membranes, and $17 \alpha$-ethinylestradiol-treated rat liver membranes were applied. Both the LDL receptor (mol wt $130,000)(24,29)$ and a band at twice this weight are identified by the anti-LDL receptor serum. $(D)$ As shown by this autoradiogram of a blot similar to that in $C$ but incubated with ${ }^{125}$ I-labeled apoE-rich $\mathrm{HDL}_{\mathfrak{c}}$, both of these bands have receptor activity. For this blot the normal rat liver membranes were loaded at 10 times the concentration of the $17 \alpha$-ethinylestradiol-treated rat liver membranes. 

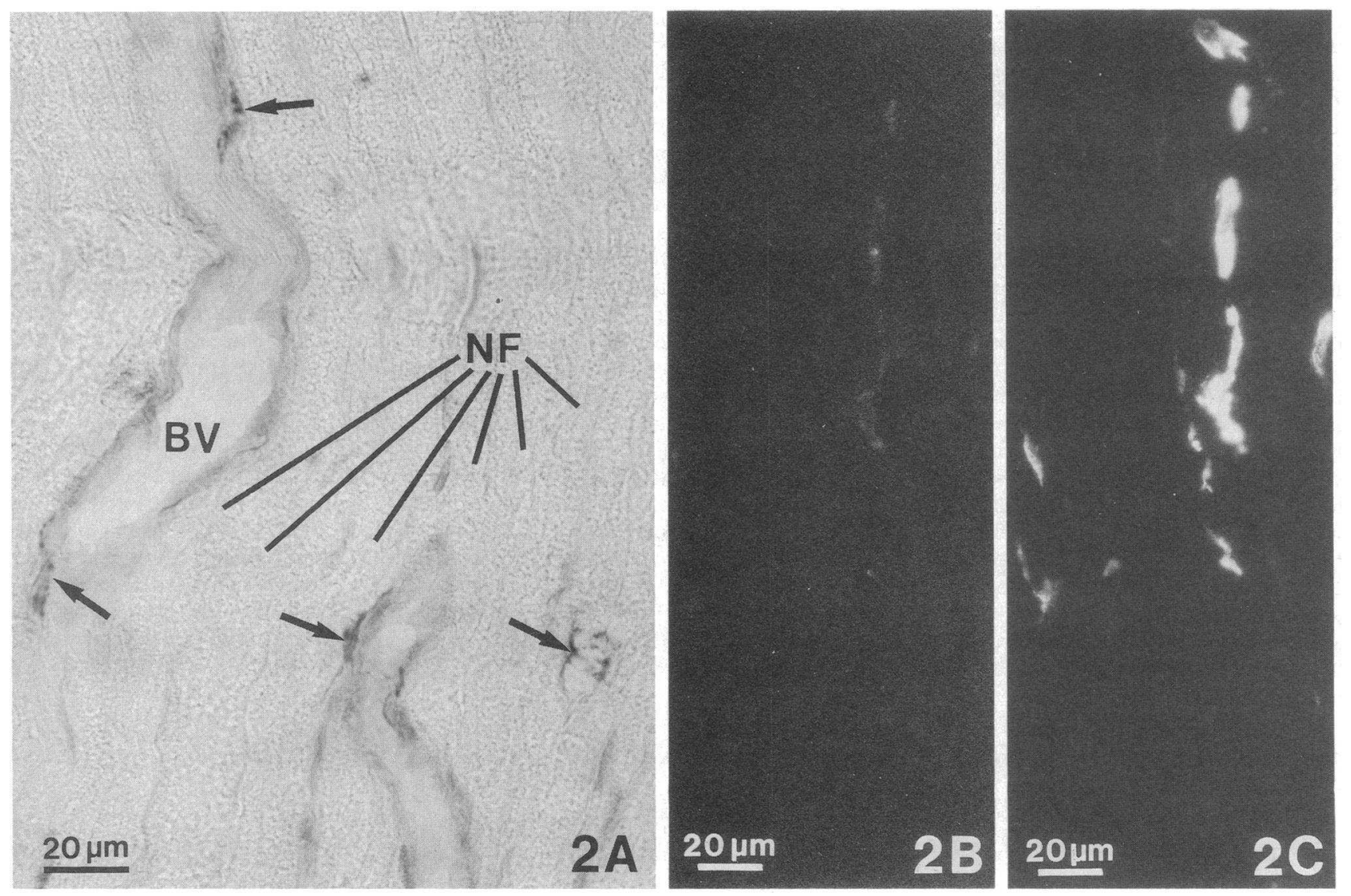

Figure 2. Micrographs of cryostat sections of normal rat sciatic nerves. $(A)$ The black peroxidase reaction product demonstrates that apoE is present primarily in cells along the blood vessels $(B V)$ or in scattered cells (arrows). $N F$, nerve fiber. ( $B$ and $C$ ) Dual fluorescence labeling of a single section for both apoE $(B)$ and macrophage-specific cell-surface markers $(C)$, identifying macrophages as the cells containing apoE. $(A)$ $\times 519 ;(B) \times 413 ;(C) \times 413$.

Inc., Palo Alto, CA) for $40 \mathrm{~h}$ at $40,000 \mathrm{rpm}$. The floating fraction was collected and applied to a heparin-Sepharose column (33), and the isolated lipoproteins were analyzed chemically for protein, phospholipid, and cholesterol (33).

\section{Results}

Normal sciatic nerve. In the normal, uninjured nerve, a weak reaction for apoE was detected in granular compartments of numerous small cells between nerve fibers (Fig. $2 A$ ). The cells reactive for apoE (Fig. $2 B$ ) were resident macrophages (Fig. 2 $C$ ), as identified by macrophage-specific cell-surface markers. Endothelial cells of small venules were also occasionally reactive for apoE. Immunoglobulin $G$ and apoA-I were not detectable in the interstitial matrix or in cells (not shown).

Degenerating sciatic nerve. Segments of rat sciatic nerves 5-15 mm distal to a crush injury were evaluated at various times. Infiltrating inflammatory cells were first seen at $2 \mathrm{~d}$ after denervation and were prominent at $3 \mathrm{~d}$. At this time, two plasma proteins, apoA-I and IgG (not shown), were detectable within the interstices of the nerve by immunochemistry. Their presence was expected, in that the injured peripheral nerve has an increased permeability to plasma proteins $(34,35)$. The numerous inflammatory cells were identifiable by their nuclear and cytoplasmic morphology as granulocytes, monocytes, and lymphocytes. None of these were reactive for apoE
(Fig. $3 A$ ). The resident macrophages (identified by their secretion of apoE) now exhibited a much higher level of reactivity for apoE (Fig. $3 \mathrm{~B}$ ) than they had in the uninjured nerve. Their foamy appearance suggested that they had also begun to accumulate lipid.

Three days after injury, electron-microscopic examination showed that both the axons and their myelin were degenerating. Numerous lipid droplets had already accumulated within Schwann cells and resident macrophages (Fig. $4 A$ ); based on previous biochemical studies, these droplets probably are cholesteryl esters (36-39).

Unusual cytoplasmic membranes were also found in many Schwann cells on the third day (Fig. 4). Numerous small disks (30-60 $\mathrm{nm}$ in diameter and 6-7 $\mathrm{nm}$ thick) as well as spheres (30-60 $\mathrm{nm}$ in diameter) resembling lipoprotein particles were found between Schwann cells and their basement membranes. The membranes and particles disappeared by $5 \mathrm{~d}$ after injury.

Regenerating sciatic nerve. By $5 \mathrm{~d}$ after injury over $80 \%$ of the Schwann cell bundles contained regenerated nerve sprouts, as observed by electron microscopy. This rapid regeneration accords with the rate of axon regrowth in the rat: $2-3 \mathrm{~mm}$ per day beginning $1-2 \mathrm{~d}$ after injury $(40,41)$. By $7 \mathrm{~d},>95 \%$ of the Schwann cell bundles contained axons, but only rarely was there evidence of myelination at this stage.

Electron microscopy also identified numerous macrophages in the nerve at 5-10 d (Fig. $5 A$ ). At $5 \mathrm{~d}$, many of these 

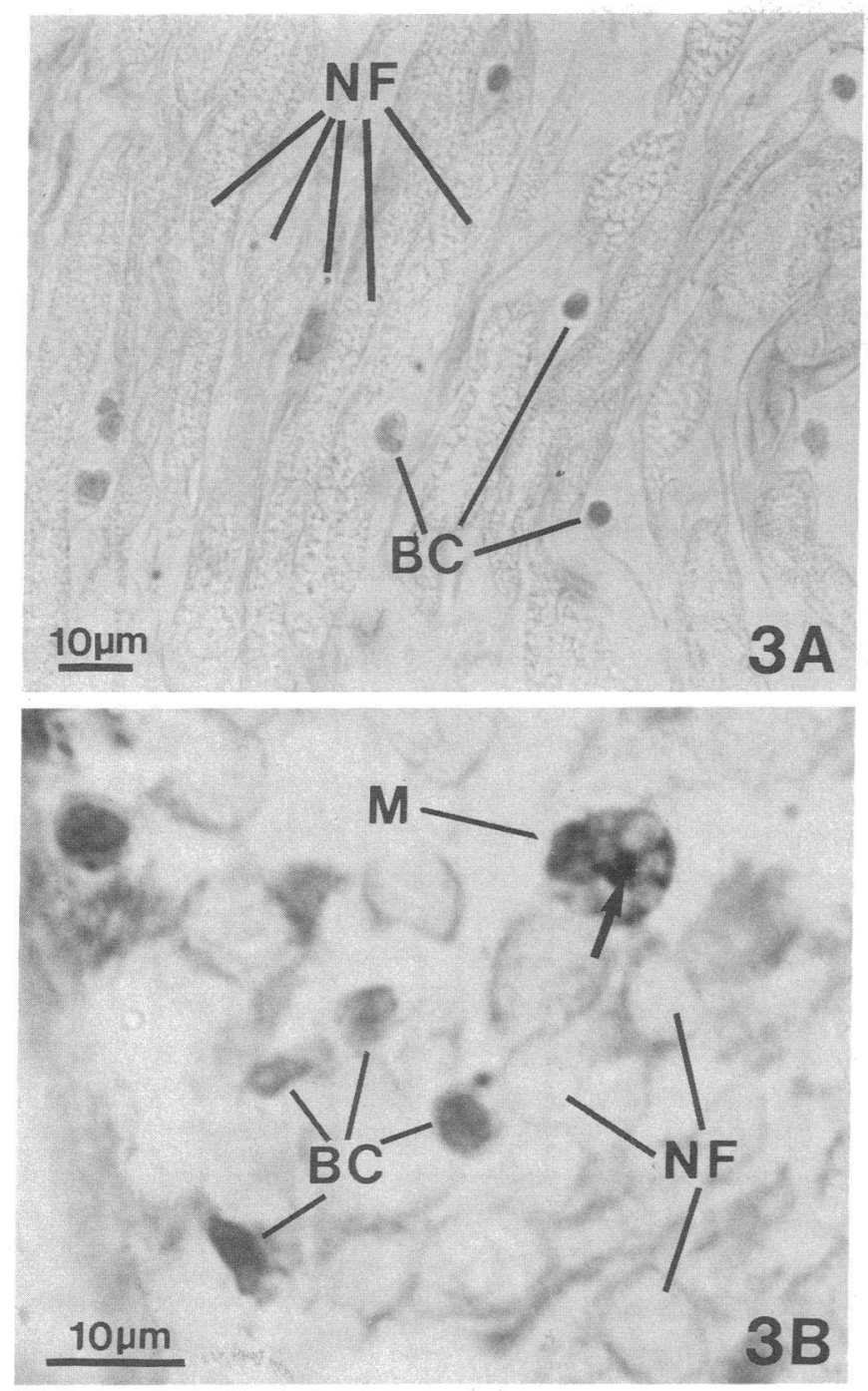

Figure 3. Micrographs of cryostat sections of a distal rat sciatic nerve fixed $3 \mathrm{~d}$ after a crush injury and processed for the immunocytochemical detection of apoE. $(A$ and $B$ ) Numerous white blood cells $(B C)$ have entered the nerve. The tissue is edematous, and the normally smooth contours of nerve fibers $(N F)$ appear irregular. Most cells of the nerve show no reaction for apoE. Occasional resident macrophages $(M)$ found between nerve fibers $(N F)$ contain dark peroxidase reaction product (arrow), indicating the presence of apoE. The cell nuclei have been counterstained. $(A) \times 730 ;(B) \times 1,440$.

interstitial macrophages still contained a few of the storage granules specific to monocytes. These macrophages contained numerous lipid droplets and a large Golgi apparatus adjacent to the nucleus, but only occasionally were endocytic or lysosomal compartments observed, near the cell periphery. The Schwann cells also contained numerous cytoplasmic lipid droplets and large lysosomal compartments filled with myelin debris.

By 5-7 d after denervation, apoE-reactive cells were prominent between Schwann cell bundles (Fig. $5 \mathrm{~B}$ ). The presence of lysozyme (not shown) within the cell and the binding of macrophage-specific monoclonal antibodies (Fig. $5 C$ ) by these cells identified them as macrophages. The apoE in these macrophages was detected as a large intense spot adjacent to the nucleus, as smaller granular spots, and as general cytoplasmic
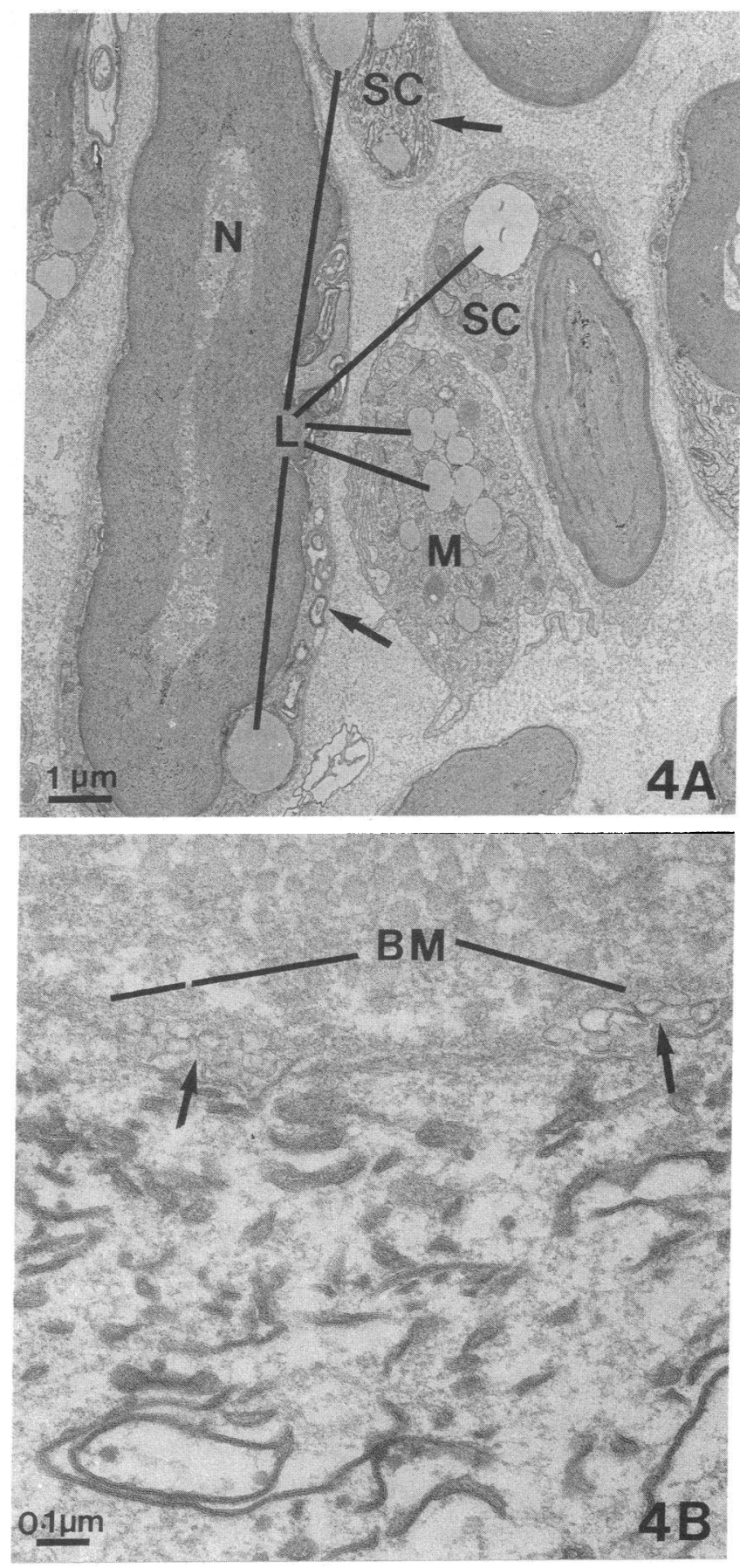

Figure 4. Electron micrographs of distal rat sciatic nerve fixed $3 \mathrm{~d}$ after crush injury. $(A)$ The myelin has already lost its regular layered structure as the Schwann cells $(S C)$ begin the process of absorption.

The nerve axons $(N)$ have completely degenerated. Lipid droplets $(L)$ are numerous not only in the cytoplasm of Schwann cells, but also in the cytoplasm of occasional resident macrophages $(M)$. Many

Schwann cells contain unusual cytoplasmic membranes that appear as collapsed vesicles or tubes and stain intensely (arrows). (B) Beneath the basement membrane $(B M)$ of these same Schwann cells are numerous bilayer disks and spherical particles that resemble lipoproteins (arrows). $(A) \times 7,250 ;(B) \times 59,400$.

reactivity (Fig. $6 \mathrm{~A}$ ). The pattern of reactivity suggests that apoE is present within the perinuclear Golgi apparatus, endosomal or lysosomal compartments, and the endoplasmic retic- 

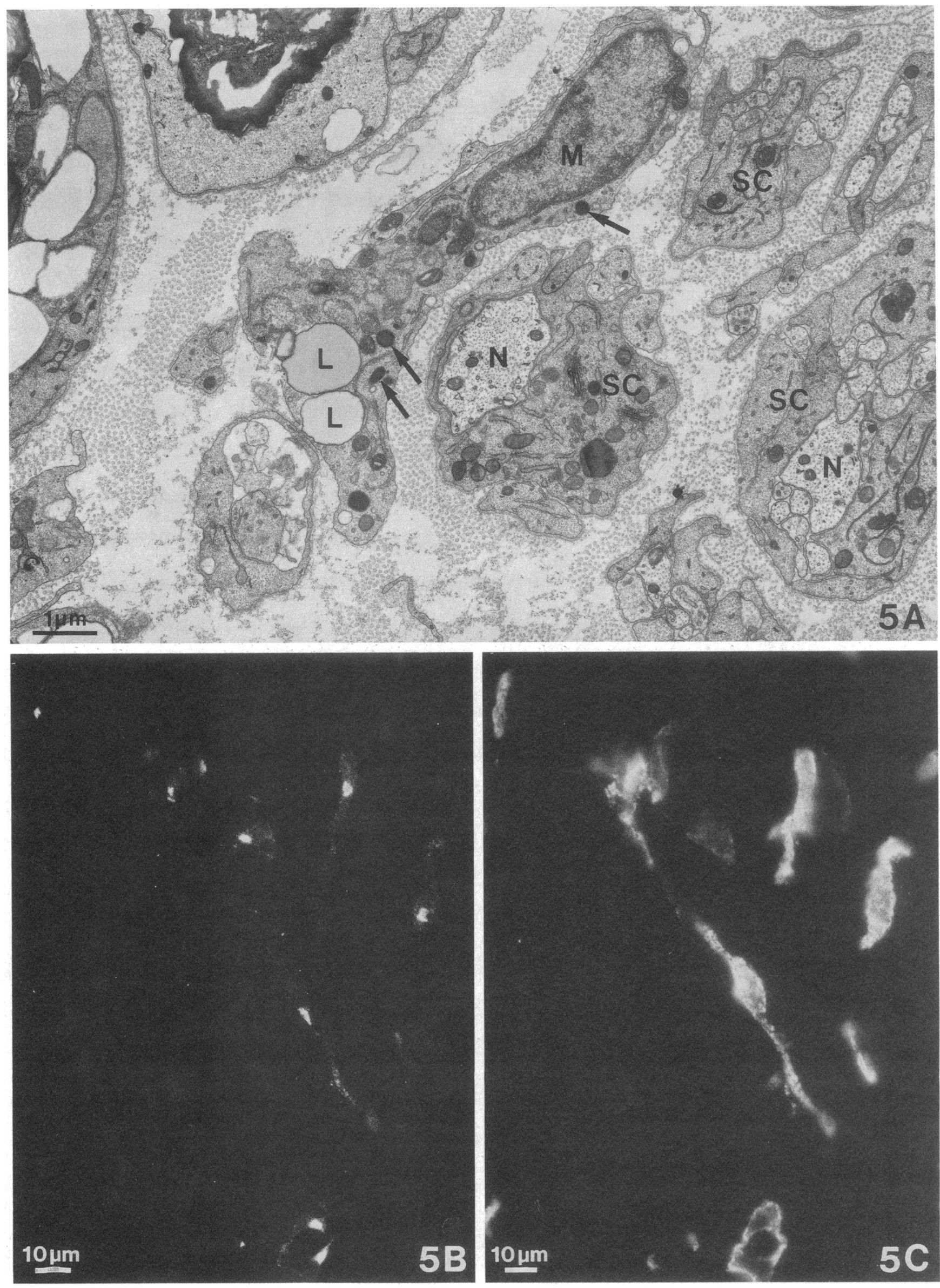

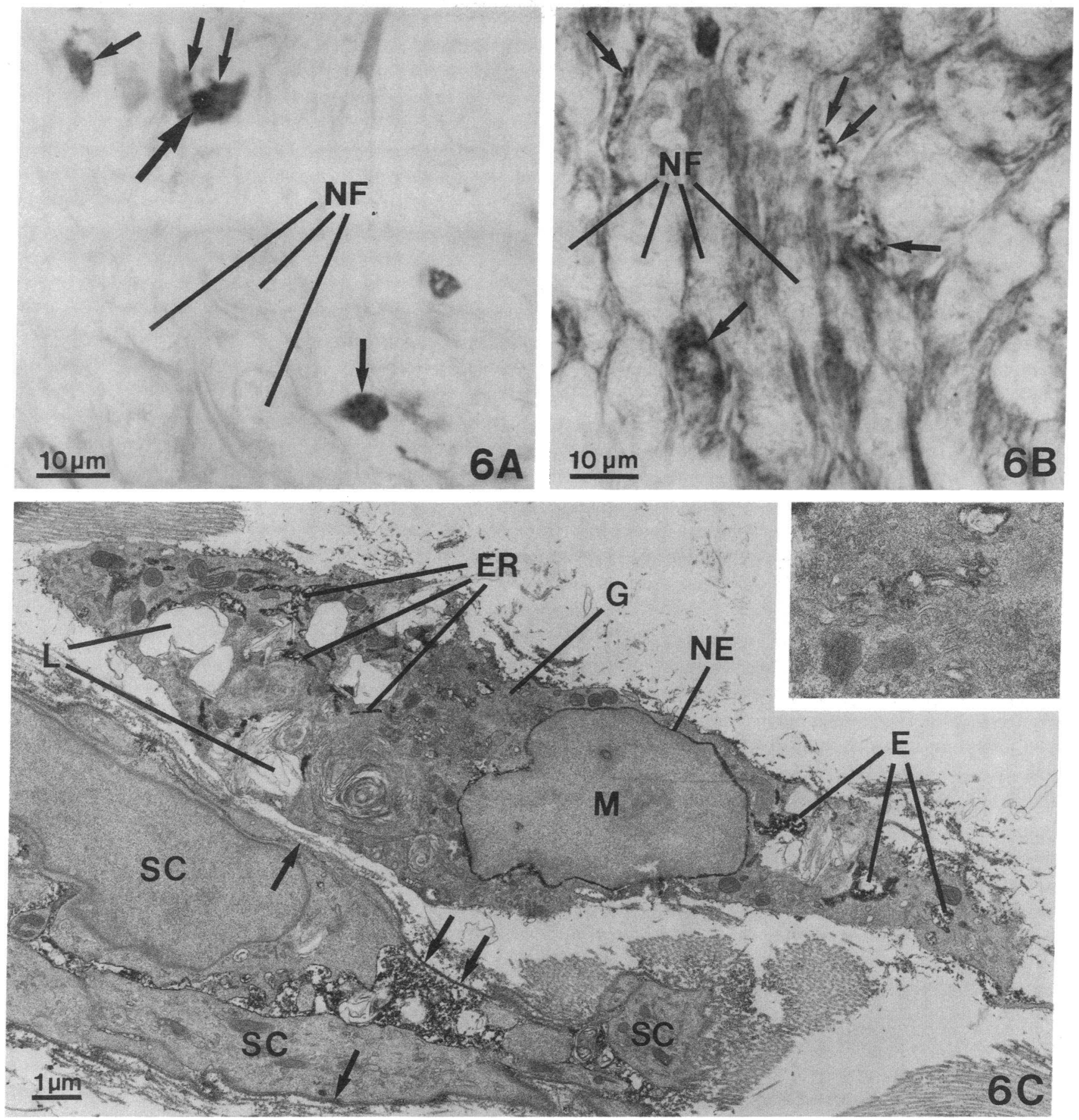

Figure 6. (A) Light micrograph of a rat sciatic nerve fixed $5 \mathrm{~d}$ after a crush injury and processed for the detection of apoE. Peroxidase reaction product denoting the presence of apoE is located in a single intense dot adjacent to the cell nucleus (large arrow), in smaller dots (small arrows) at the periphery of the cells, and generally throughout the cell. $(N F)$ Nerve fiber. (B) Light micrograph of a second section of the same nerve processed for the detection of apoA-I. ApoA-I, unlike apoE, is present throughout the space between nerve fibers $(N F)$. It is also found as a small granular reaction within macrophages (arrows). However, no reaction for apoA-I is seen in the Golgi region of any cell. ( $C$ ) Electron micrograph of a rat sciatic nerve fixed $\mathbf{8 d}$ after injury and processed for the detection of apoE. Dark peroxidase reaction product is present in the nuclear envelope $(N E)$, the endoplasmic reticulum $(E R)$, the Golgi apparatus $(G)$ (enlarged in inset), and what appear to be endosomal compartments $(E)$ of a lipid-filled $(L)$ macrophage $(M)$. Reaction for apoE can also be found between Schwann cells $(S C)$, within their basement membranes (arrows), and occasionally in the extracellular matrix. $(A) \times 1,200 ;(B) \times 1,200 ;(C) \times 8,200 ;$ (inset) $\times 21,600$.

Figure 5. (A) Electron micrograph of a section of distal rat sciatic nerve fixed $5 \mathrm{~d}$ after a crush injury. Many Schwann cell bundles $(S C)$ already contain nerve axons $(N)$. A monocyte-derived macrophage $(M)$ is seen between the regenerating nerve fibers. The macrophage still contains many monocyte storage granules (arrows), but it has also acquired lipid droplets $(L)$. ( $B$ and $C$ ) Micrographs of a single cryostat section of rat sciatic nerve fixed $7 \mathrm{~d}$ after injury and processed with dual fluorescence labeling for the detection of both apoE $(B)$ and macrophage surface markers $(C)$. Apolipoprotein $\mathrm{E}$ is found within numerous cells displaying macrophage-specific antigen. $(A) \times 12,400 ;(B) \times 600 ;(C) \times 600$. 
ulum. Apolipoprotein A-I (Fig. 6 B) and IgG (not shown), which were present in the interstitial matrix, were also found in granular compartments of these macrophages, suggesting that macrophages had internalized lipoproteins and proteins from the matrix.

Immunocytochemistry at the electron-microscopic level confirmed the subcellular localization of apoE. Using a peroxidase-based pre-embedding technique for antigen detection, we found apoE in morphologically identifiable macrophages 7-10 d after injury (the high point of apoE secretion [1]). In sections incubated with anti-apoE, peroxidase reaction product was seen in the nuclear envelope, the endoplasmic reticulum, and the Golgi apparatus with its associated vesicles, as well as occasionally in what appeared to be lysosomal or endosomal compartments of macrophages (Fig. $6 \mathrm{C}$ ). Neurolemmal fibroblasts and Schwann cells were never observed to contain apoE. With the occasional exception of endothelial cells in small venules, no other cells were reactive for apoE. Some apoE was detected between the processes of interlocking Schwann cells and in the extracellular matrix. This is consistent with results from previous biochemical studies $(1,2,5)$ and our own light-level immunocytochemical studies, which suggest that apoE begins to accumulate during the second week after injury.

There was no immunochemical evidence, at either the light- or electron-microscopic level, of apoA-I secretion by any cells in the nerve. This is consistent with earlier biochemical studies, which found no evidence for the production of a protein of the appropriate molecular weight by the denervated sciatic nerve $(1,2)$. Therefore, in injured nerves, apoA-I, like IgG and albumin $(34,35)$, appears to originate from the plasma.

Remyelinating sciatic nerve. By $14 \mathrm{~d}$, remyelination of the larger axons was well under way (Fig. 7): many axons were surrounded by one or more layers of myelin.

The distribution of apoE and apoA-I changed dramatically between 7 and $14 \mathrm{~d}$. The bands of Schwann cells (or nerve fibers) now showed an intense surface reaction for both apoE and apoA-I (Fig. 8). Their accumulation in the nerve was not due to a general accumulation of plasma proteins, as shown by the fact that the level of IgG remained constant (not shown) following its initial rise soon after the crush injury.

Immunocytochemistry showed that the distribution of apoE and apoA-I remained essentially unchanged from 14 to $21 \mathrm{~d}$, except for increased apoE in the matrix and the loss of the intense reaction for apoE near the nucleus in a few macrophages. By $28 \mathrm{~d}$, reaction for apoE had either disappeared from the Golgi region or was substantially diminished in every macrophage (Fig. 9). Thus, it appeared that apoE production by macrophages was greatly reduced by $28 \mathrm{~d}$. This is in keeping with earlier biochemical work, which found that apoE accumulates in the nerve after apoE production has dropped $(1,2,5)$.

Electron microscopy 21 and $28 \mathrm{~d}$ after injury showed that the percent of Schwann cells with myelin sheaths had risen and that these sheaths were wider (Fig. $10 \mathrm{~A}$ ). With rare exceptions, Schwann cells that had produced myelin no longer contained lipid droplets. The cholesterol stores of these myelinating cells presumably had been used to synthesize the myelin that now enveloped the axons. This is in agreement with biochemical measurements that show that cholesteryl esters in the injured nerve decline after the second and third weeks (39). The cho-

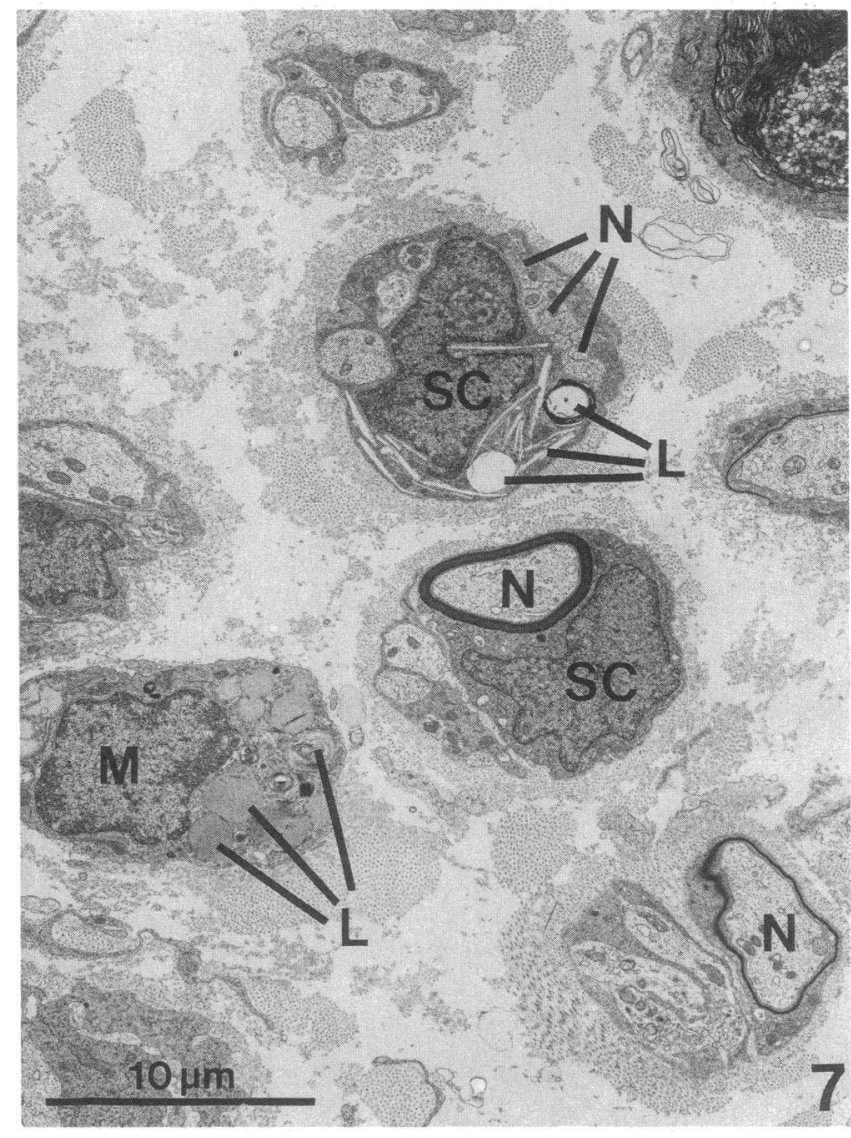

Figure 7. Electron micrograph of a section of distal rat sciatic nerve fixed $14 \mathrm{~d}$ after a crush injury. At this time many of the Schwann cells $(S C)$ surrounding nerve axons $(N)$ have begun to remyelinate these axons. A few Schwann cells still contain lipid droplets $(L)$, and macrophages $(M)$ have numerous lipid droplets, which are more osmophilic than those of the Schwann cell or neurolemmal fibroblast. $\times 2,700$.

lesteryl ester stores remaining in the nerve were present in the macrophages and neurolemmal fibroblasts.

The nerve matrix also exhibited morphologic changes at this time. Increasing concentrations of discoidal particles 6-7 $\mathrm{nm}$ wide and 15-200 $\mathrm{nm}$ in diameter were found in the amorphous matrix and to a lesser extent between collagen bundles (Fig. 10) in the third and fourth weeks. These particles resemble the disks formed by apoE and apoA-I when mixed with phospholipids (42). The appearance of these discoidal particles in the extracellular matrix at this time coincided with the peak of apoE accumulation, 21-28 d after denervation (1, 2, 5). For the first time, the matrix also contained large amounts of membrane debris. The debris was often found in clusters that contained lipid droplets and recognizable cellular organelles, suggesting that it was derived from disintegrating macrophages.

Surviving macrophages had a noticeably altered morphology at this stage. These cells were large (10-20 $\mu \mathrm{m}$ in diameter), and in addition to lipid droplets they now contained large numbers of membrane-enclosed compartments filled with vesicles and lamellar lipid (Fig. 10, $A$ and $B$ ). These apparently were lysosomes and endosomes. Compartments at the perime- 

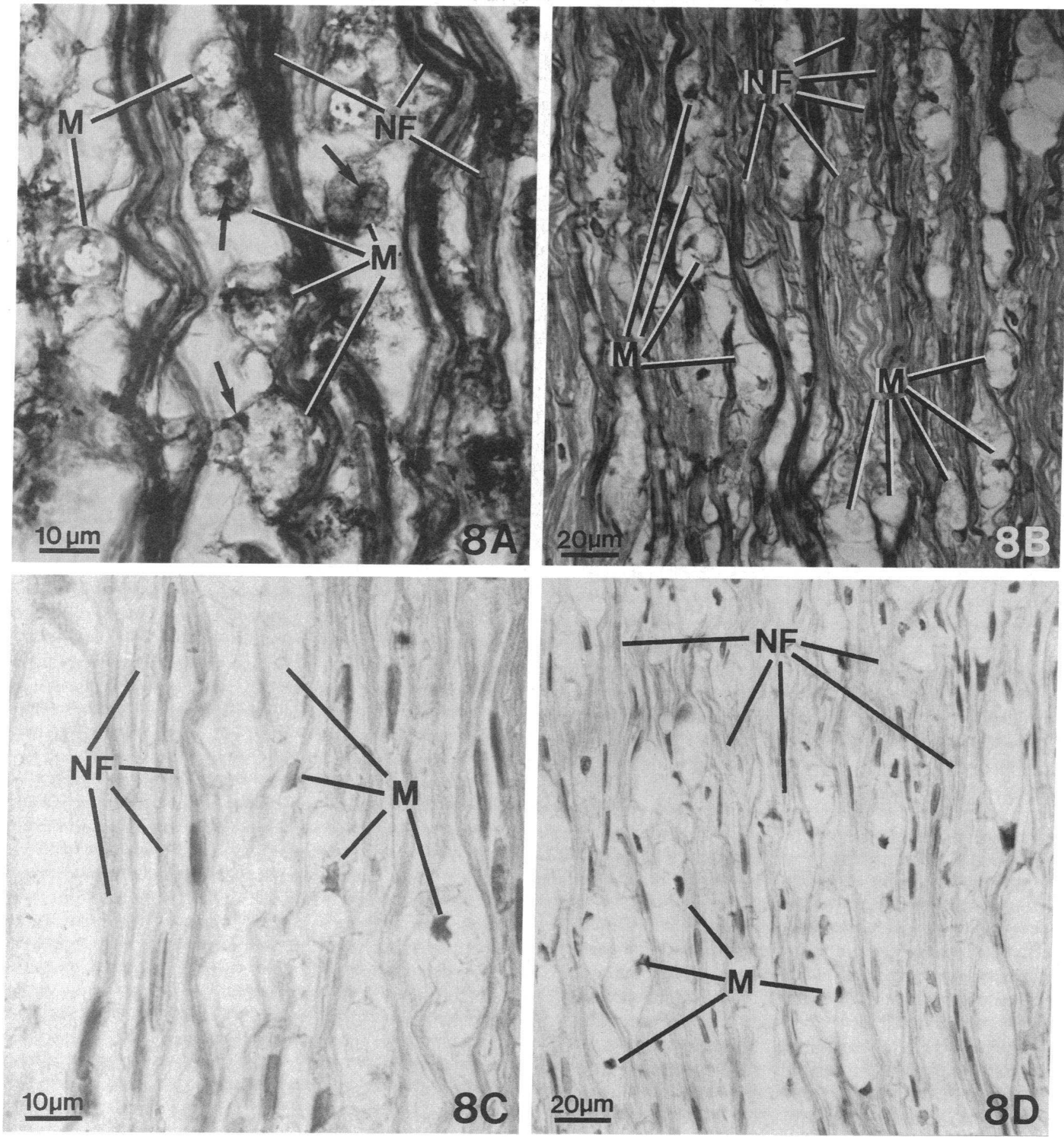

Figure 8. Micrographs of cryostat sections of distal rat sciatic nerves fixed $14 \mathrm{~d}$ after a crush injury. $(A)$ This section was processed for the immunocytochemical detection of apoE. The nerve fibers $(N F)$ have been teased apart to demonstrate more precisely the location of apoE coating the nerve fibers. The macrophages $(M)$ between nerve fibers are large and lipid-filled. An intense dot of reactivity for apoE is seen adjacent to the nucleus (arrows) of these macrophages, with smaller areas of reactivity at the perimeter of the cell. $(B)$ This section, in which the nerve fibers have not been teased apart, was processed for the detection of apoA-I. Dark peroxidase reaction product identifies apoA-I along the surface of the vertically oriented nerve fibers $(N F)$ and between lipid-filled macrophages $(M)$. Cell nuclei have been counterstained in this example to make them visible. $(C)$ This section, which has not been teased apart, was processed with preimmune serum from the rabbit used to raise the apoE-specific antibody. The cell nuclei have been counterstained. $(M)$ Macrophage; $(N F)$ nerve fiber. $(D)$ This section was reacted with preimmune serum from the rabbit used to raise the apoA-I antibody. The cell nuclei have been counterstained. $(M)$ Macrophage; $(N F)$ nerve fiber. $(A) \times 890 ;(B) \times 440 ;(C) \times 890 ;(D) \times 440$.

ter contained discoidal particles, membrane debris, and small multilamellar vesicles, whereas more central compartments were filled with gigantic whorls of lamellar lipid. There was no evidence that macrophages directly secrete the discoidal particles, e.g., no particles were ever seen in their Golgi apparatus. The morphologic evidence suggests, rather, that macrophages 


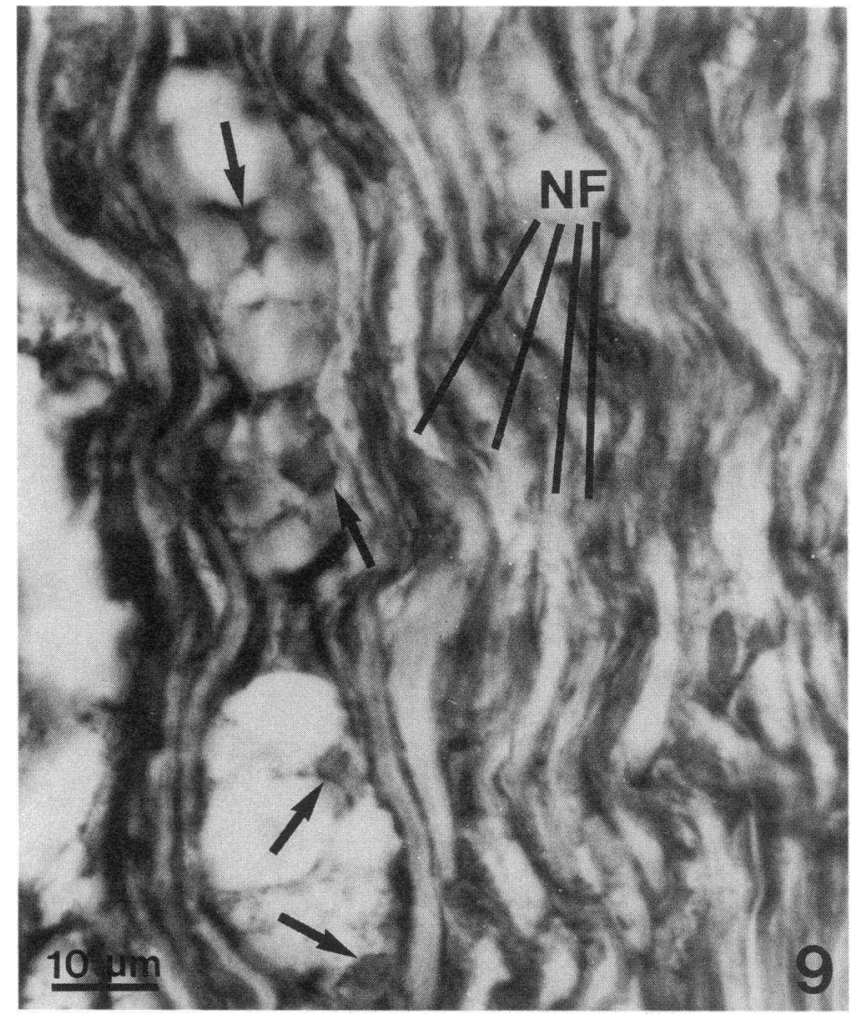

Figure 9. Micrograph of a cryostat section of distal rat sciatic nerve fixed $28 \mathrm{~d}$ after a crush injury. The section was processed for the detection of apoE. The nuclei in this section have been counterstained to make them more easily identifiable. The intensity of the apoE reactivity adjacent to the nucleus (arrows) in lipid-loaded macrophages is diminished, but dark peroxidase reaction product continues to fill the interstitial space and coats the nerve fibers $(N F) . \times 1,060$.

take up discoidal particles from the matrix. Presumably the particles are formed in the matrix.

At no time point did neurolemmal fibroblasts contain compartments filled with membrane debris or discoidal particles. Similarly, few Schwann cells had lysosomes containing even one or two small multilamellar vesicles, although some Schwann cells contained larger debris-filled lysosomes. Discoidal particles were rarely seen beneath the basement membranes of Schwann cells and were never seen within the basement membranes of capillaries, suggesting they are rapidly cleared from this space or do not readily permeate basement membranes.

From $28 \mathrm{~d}$ onward, as remyelination proceeded toward completion, less and less apoE and apoA-I were detected. By $56 \mathrm{~d}(8 \mathrm{wk})$, the morphologic appearance of the nerve had nearly returned to normal. However, the interstitial macrophages were still more numerous than in the normal nerve, and many still had a foamy appearance. The levels of apoE, apoA-I, and IgG also were still above normal. By $105 \mathrm{~d}$ (15 wk) the nerve appeared to be essentially normal, except for a few more macrophages than before the lesion. Apolipoprotein E was occasionally present adjacent to the nucleus in the Golgi region of these cells, suggesting that macrophages continue to secrete slightly increased amounts of apoE for some time.

Morphometric analysis of lipid distribution. The changing distribution of lipid during regeneration was demonstrated by a morphometric analysis: the percent of the total cell volume of the nerve occupied by lipid droplets in Schwann cells was compared with that in macrophages and neurolemmal fibroblasts at several time points (Table I). Lipid droplets in Schwann cells were most prominent 1 and 2 wk after injury. By 3 wk the volume of lipid droplets in Schwann cells declined sharply, just as the volume of myelin increased dramatically. The volume of lysosomes and endosomes in these cells also decreased sharply by $3 \mathrm{wk}$, suggesting that the myelin debris within lysosomes may also represent stored lipid. During the third week, macrophages and neurolemmal fibroblasts exhibited an increase both in volume and the percent of that volume occupied by lipid droplets and lysosomes or endosomes. The lipid stores of macrophages and neurolemmal fibroblasts began to decline in the fourth and fifth weeks, after Schwann cell lipid stores had declined.

Characterization of lipoproteins in remyelinating nerve. To determine whether apoE and apoA-I were associated with the discoidal particles in the matrix, distal sciatic segments were extracted 4 wk after injury and their lipoproteins were separated by density. The apoE-containing lipoproteins were then isolated by binding to heparin $(43,44)$. The bound fraction consisted of discoidal particles similar to those seen in thin sections of the nerve matrix, as well as smaller, 10 - to $30-\mathrm{nm}$ spherical particles (Fig. 11). Most of these particles were smaller than those recognized in thin sections and probably are too small to be identifiable in those sections. No lipoprotein particles could be identified in the extracts from normal nerves.

Chemical analysis of the heparin-bound lipoprotein particles from two isolations showed that their average mass was $29 \%$ protein, 33\% phospholipid, and 38\% cholesterol. Most (77\%) of the cholesterol was nonesterified. The low content of cholesteryl ester, which forms the core of spherical plasma lipoproteins, is in keeping with the discoidal nature of many of these particles.

The proteins of the bound and unbound fractions were further analyzed by SDS-PAGE (Fig. 12). ApoE was the major component of the bound fraction, but apoA-I was also found largely in the bound fraction. Because apoA-I does not bind to heparin, it must be on the same particles as apoE. A smaller fraction of apoA-I was found in the unbound fraction and may be part of the few lipoproteins found in this fraction. The majority of the protein in the unbound fraction apparently was albumin $(66 \mathrm{kD})$.

Expression of low density lipoprotein receptors. In the normal nerve, a low level of reaction for LDL receptors was consistently seen along the surfaces of Schwann cells and macrophages (data not shown). Sporadic, low reactivity was seen in axons as well. However, as axons began to regenerate through the distal segment within the first week after injury, intense reactivity for LDL receptors was identified in fibers seen at the surface of Schwann cell cords (Fig. 13, $A$ and $B$ ). Many of these fibers were reactive for distances up to $500 \mu \mathrm{m}$. As axon regeneration was completed through the segment immediately distal to the site of injury, reactivity was detectable only more distally. In any short distal section of nerve during a given day after injury, only a few reactive fibers were found, perhaps because of the differing growth rates of axons.

Antibodies to neurofilaments were used to establish that the LDL receptor-positive fibers were in fact the growing tips of regenerating axons. Many fibers (approximately one-third) 

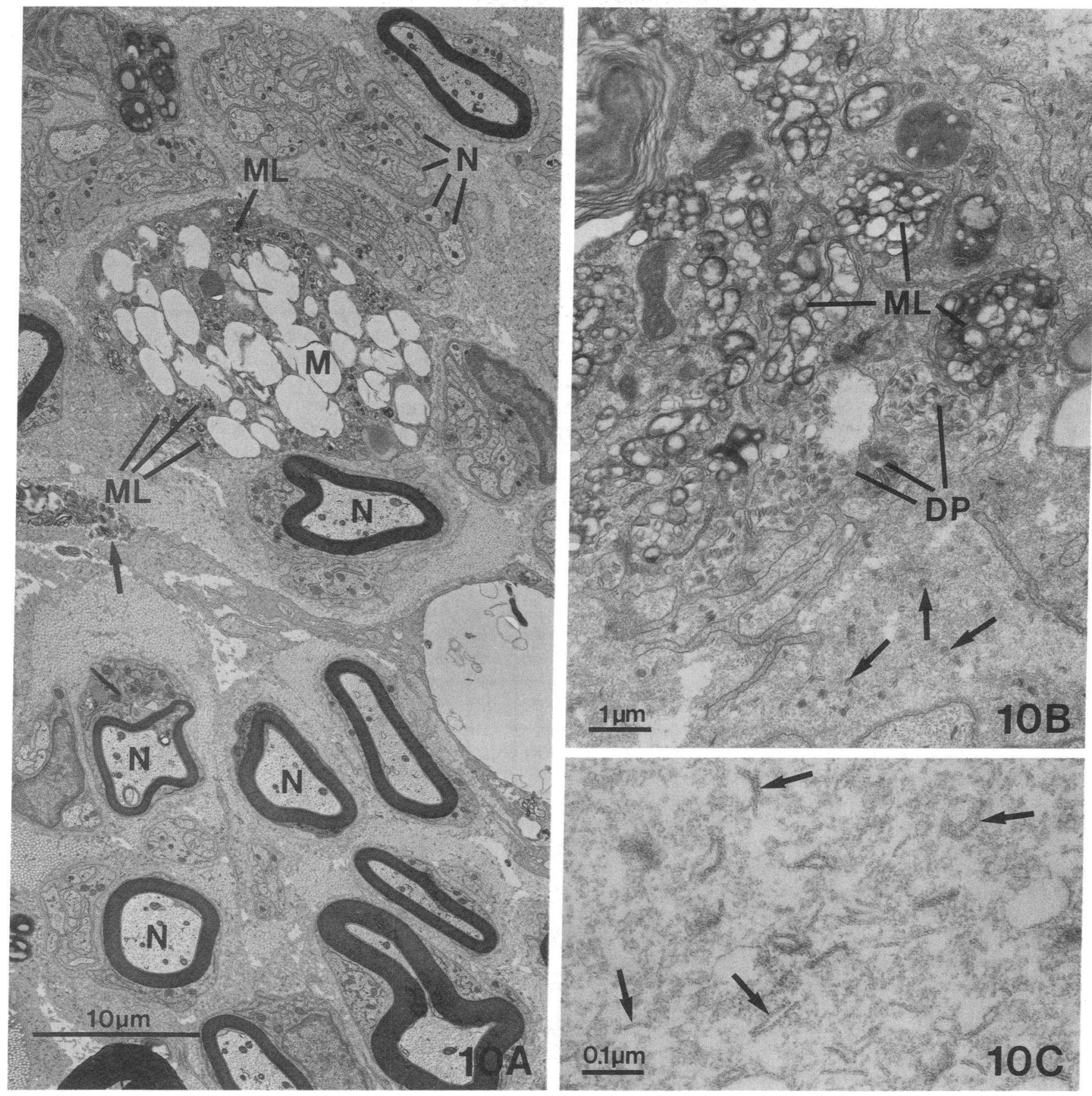

Figure 10. Electron micrographs of sections of distal rat sciatic nerve fixed $28 \mathrm{~d}$ after a crush injury. $(A)$ The Schwann cells have now greatly increased the thickness of the myelin layers surrounding nerve $(N)$ axons. Lipid droplets are still present in the interstitial macrophages $(M)$ but not in the cytoplasm of Schwann cells. Lipid whorls and membrane debris are present in the matrix of the tissue (arrow). Within the macrophage, numerous compartments filled with multilamellar lipid $(M L)$ are also found. $(B)$ At the periphery of macrophages such as this one are compartments filled with discoidal particles $(D P)$ and multilamellar lipid $(M L)$. Within the matrix of the tissue are numerous small discoidal particles (arrows). $(C)$ The discoidal particles of the matrix, some of which are marked with arrows, are seen at higher magnification in this very thin section. $(A) \times 2,700 ;(B) \times 10,000 ;(C) \times 97,000$.

were reactive for both $\mathrm{LDL}$ receptors (Fig. $13 C$ ) and neurofilaments (Fig. $13 \mathrm{D}$ ), whereas others were positive for only one of these antigens. This result is not surprising: neurofilaments are most prominent in the older portion of the growing axon, whereas reaction for LDL receptors appeared to be confined largely to the advancing tips. Expression of LDL receptors at the front of growing axons accords with the uptake of apoEcontaining lipoproteins by the growth cones of rat PC 12 cells in culture (45).

The reaction for LDL receptors along growing axons was exceptionally intense. Successive dilutions of antibody to the LDL receptor were used to determine the relative concentra- 
Table I. Morphometric Analysis of Cellular Volume in the Denervated Rat Sciatic Nerve

\begin{tabular}{|c|c|c|c|c|c|c|c|c|}
\hline & \multirow[b]{2}{*}{$\begin{array}{l}\text { Axons: } \\
\text { total }\end{array}$} & \multicolumn{4}{|c|}{ Schwann cells } & \multicolumn{3}{|c|}{ Macrophages and fibroblasts } \\
\hline & & Total* & $\begin{array}{l}\text { Lysosomes and } \\
\text { endosomes }\end{array}$ & $\begin{array}{c}\text { Lipid } \\
\text { droplets }\end{array}$ & Myelin & Total $^{*}$ & $\begin{array}{l}\text { Lysosomes and } \\
\text { endosomes }\end{array}$ & $\begin{array}{c}\text { Lipid } \\
\text { droplets }\end{array}$ \\
\hline & $\%$ & \multicolumn{4}{|c|}{$\%$} & \multicolumn{3}{|c|}{$\%$} \\
\hline Normal sciatic & 19 & 77 & 0 & 0 & 62 & 5 & 0 & 0 \\
\hline $1 \mathrm{wk}$ & 5 & 79 & 37 & 3 & 0 & 17 & 0 & 1 \\
\hline $2 \mathrm{wk}$ & 8 & 64 & 30 & 3 & 7 & 28 & 9 & 3 \\
\hline 3 wk & 18 & 52 & 5 & 1 & 22 & 31 & 13 & 5 \\
\hline 4 wk & 16 & 59 & 7 & 1 & 28 & 26 & 16 & 3 \\
\hline $6 \mathrm{wk}$ & 23 & 59 & 4 & 0 & 49 & 19 & 11 & 2 \\
\hline $8 w k$ & 25 & 63 & 1 & 0 & 54 & 12 & 5 & 0 \\
\hline
\end{tabular}

All values are the average of results from two animals and have been rounded off to the nearest integer. All values are expressed as a percentage of the total cellular volume of the nerve, not as a percentage of the volume for each cell type. This was done to facilitate direct comparisons between cell types. * The values in this column are the cellular volumes of this cell type. Summation of the total volumes of Schwann cells, axons, and macrophages and fibroblasts equals $100 \%$ of the cellular volume of the nerve.

tions of receptor in neurons and several other tissues. The reaction at the growing tips of axons was greater than that seen either in steroidogenic tissues (adrenal, testis, and ovary) or the liver, but was comparable to that seen in the liver and adrenals of animals treated with $17 \alpha$-ethinylestradiol to stimulate expression of LDL receptors (J. K. Boyles, unpublished observation).

The level of LDL receptors along Schwann cells remained reduced until the third week after injury. At this point the Schwann cells, having begun remyelination, had largely exhausted their cholesterol stores (Fig. $10 \mathrm{~A}$ and Table I). Receptor expression increased in Schwann cells (Fig. $14 A$ ) but not in macrophages, which at this time still contained cholesteryl esters. The level of receptors on Schwann cells remained increased through the eighth week (56 d). By the end of the fifteenth week (105 d), receptor activity in Schwann cells had declined to the low level (Fig. $14 \mathrm{~B}$ ) detected in the normal nerve, and low levels of receptors characteristic of normal nerve were once again detectable in macrophages.

\section{Discussion}

The present study provides evidence for a lipid (specifically, cholesterol) transport mechanism involving apoE and its re-
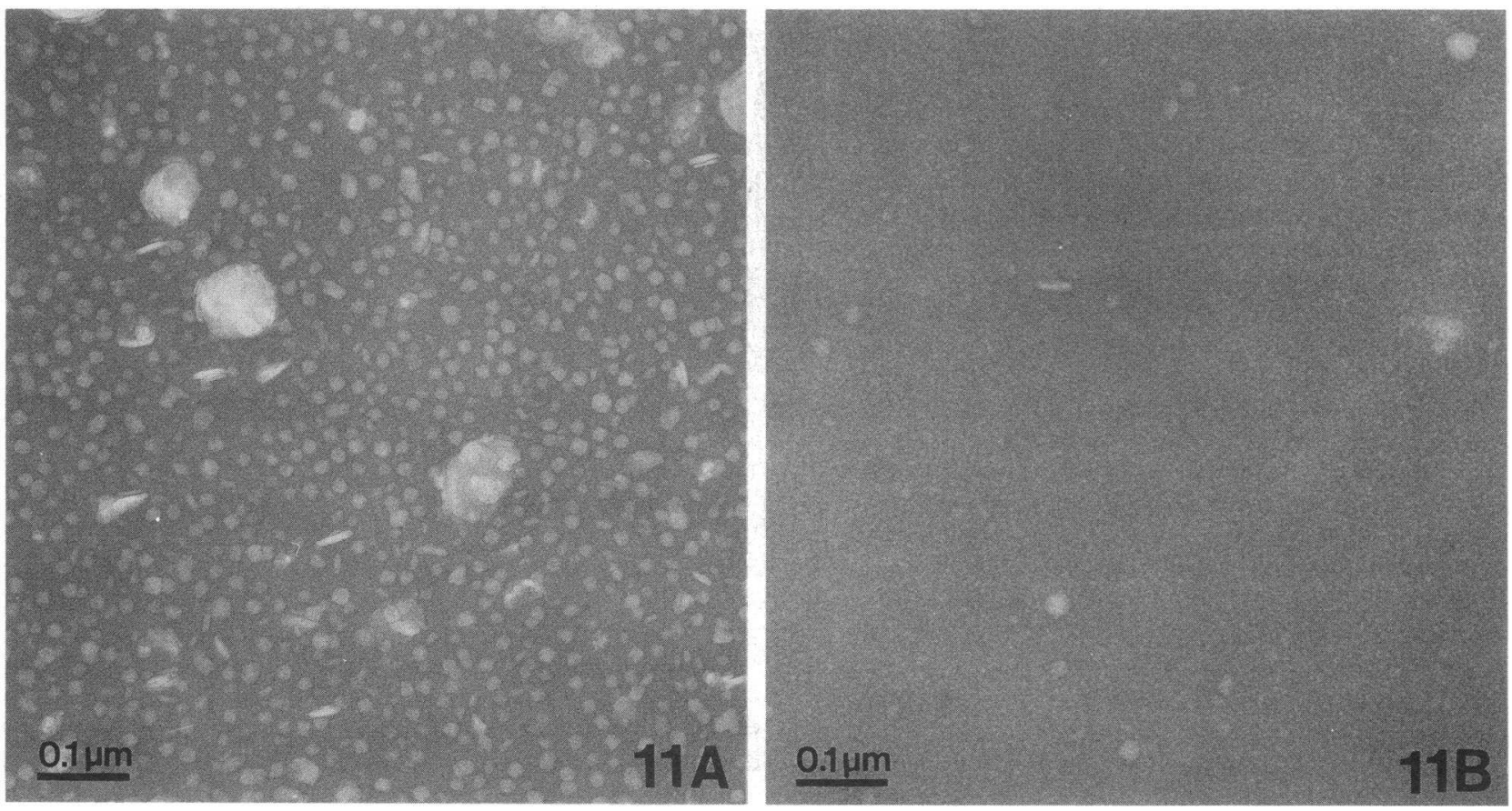

Figure 11. Negative stains of the $d<1.21 \mathrm{~g} / \mathrm{ml}$ fraction extracted from blood-free distal rat sciatic nerves $28 \mathrm{~d}$ after a crush injury. $(A)$ The heparin-Sepharose column-bound and -eluted fraction. $(B)$ The heparin-Sepharose column flow-through, or unbound, fraction. $(A) \times 100,000 ;(B)$ $\times 100,000$. 


\section{Coomassie Blue}

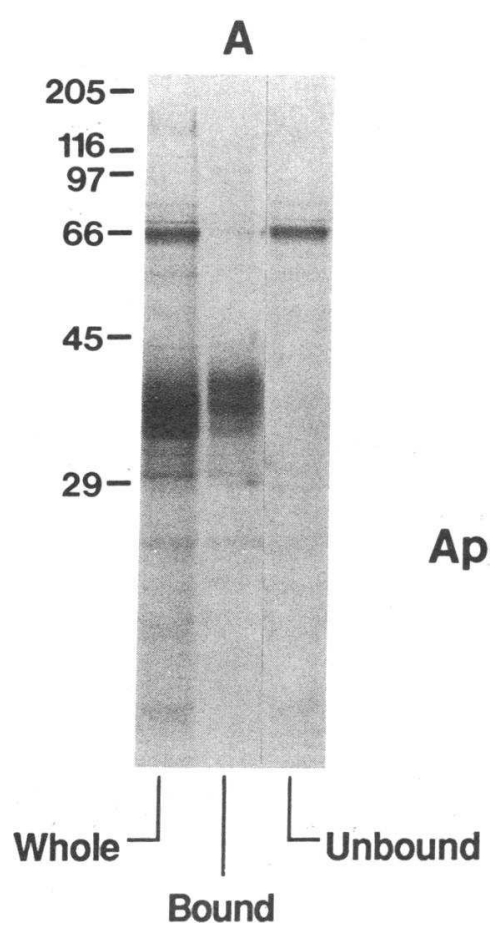

Anti-Apo-A-I

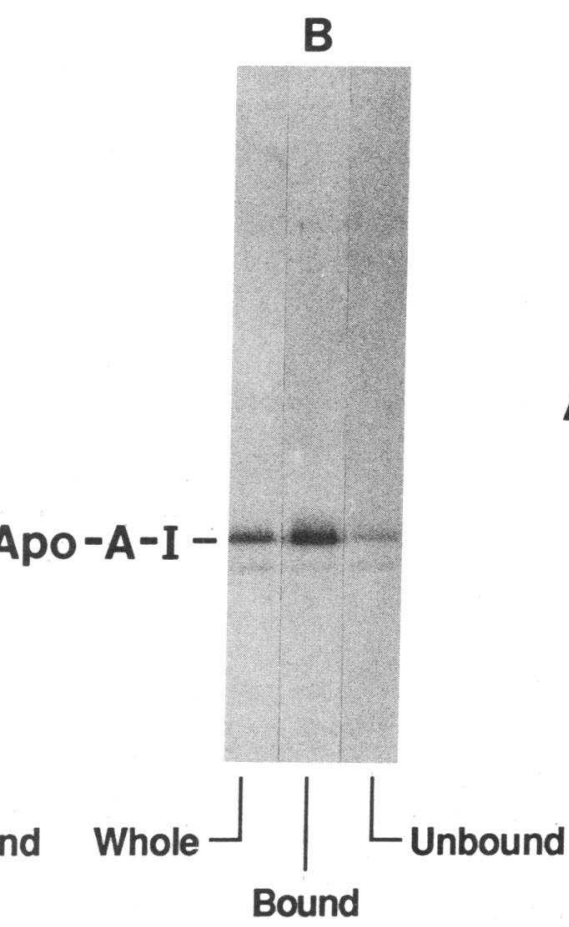

Anti- Apo-E

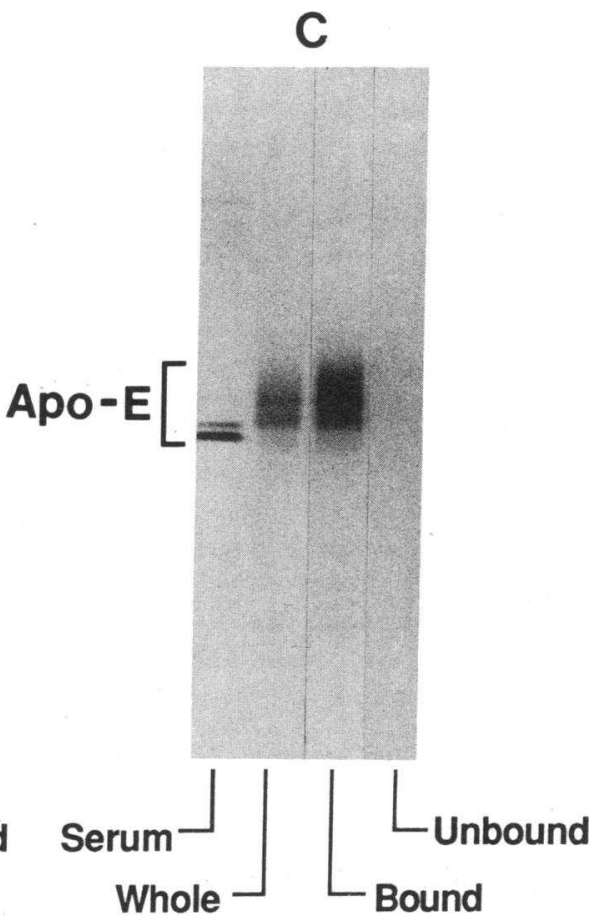

Figure 12. Characterization of the $d<1.21 \mathrm{~g} / \mathrm{ml}$ fraction isolated from blood-free distal sciatic nerves $28 \mathrm{~d}$ after a crush injury. (A) Coomassie blue-stained, reduced, and denatured $10 \%$ SDS-polyacrylamide gel to which were added equal quantities of the whole $d<1.21 \mathrm{~g} / \mathrm{ml}$ fraction, the portion that bound to heparin-Sepharose, and the portion that did not bind. $(B)$ In this blot, of a similar gel incubated with anti-apoA-I, a major band at $28 \mathrm{kD}$ (the molecular mass of apoA-I) and a smaller-molecular-mass band are identified. The latter is probably a breakdown product of apoA-I. A peroxidase reaction was used to identify the bound rabbit antibodies. $(C)$ On a similar blot, anti-apoE antibodies identify a very broad region between 36 and $42 \mathrm{kD}$. An upward shift in molecular mass is characteristic of sialylated apoE, as shown in normal rat serum by the major band of asialo apoE at $34 \mathrm{kD}$ and the minor band of monosialylated apoE at $36 \mathrm{kD}$.

ceptor in the normal, degenerating, and regenerating nerve. We have documented the temporal sequence of peripheral nerve regeneration with respect to increased apoE secretion and accumulation in the nerve, apoA-I entry and accumulation, LDL receptor expression, and lipid redistribution. The time course of these events is summarized in Table II. In the normal sciatic nerve, only a small amount of apoE is produced, primarily by resident macrophages (Fig. 2). After denervation injury, resident macrophages and then monocytederived macrophages produce apoE in large quantity (Figs. 3, 5 , and 6) as myelin is absorbed by Schwann cells and as axons degenerate (Fig. 4). ApoA-I, in contrast to apoE, enters the nerve along with other plasma constituents. Droplets of cholesteryl ester are stored by macrophages and Schwann cells during degeneration (Figs. $4 A, 5 A$, and 7) $(12,13,46)$ and are reused during regeneration (12-14). As axons regenerate, their advancing tips express high levels of LDL receptors (Fig. 13). In the portion of the nerve used in our study $-5-15 \mathrm{~mm}$ distal to the crush site-regeneration of axons is essentially complete by 7-8 d after injury. Remyelination of these axons begins before day 14 after injury (Fig. 7). By $21 \mathrm{~d}$, remyelination is well advanced and myelinating Schwann cells have nearly exhausted their cholesteryl ester stores (Table I, Fig. $10 \mathrm{~A}$ ). At this time Schwann cells express increased numbers of LDL receptors (Fig. $14 A$ ). Macrophages and neurolemmal fibroblasts still contain cholesteryl ester stores, which in turn are depleted over the next several weeks as myelination continues (Table I). During remyelination, apoE and plasma-derived apoA-I accumulate in great concentrations in the interstices of the nerve as components of cholesterol-rich lipoproteins (Figs. 8-12).

This study demonstrates that cholesterol-loaded macrophages are the major producers of apoE in the injured nerve. This finding is consistent with the established role of the macrophage in the production of this protein. Both resident and monocyte-derived macrophages produce apoE in vitro, whereas fresh blood monocytes or monocytes during their first days in culture do not (47-50). The rate of apoE production is in part regulated by the cholesterol content of the cell (48); for example, apoE production rises in macrophages ingesting cholesterol-rich material and accumulating cholesterol (48). It is plausible, therefore, that as macrophages in the injured nerve rapidly fill with cholesteryl esters, they would also produce more apoE. Similarly, as cholesteryl esters in these cells are depleted, a drop in apoE production is expected. This also appears to occur in vivo, as our morphology data and earlier biochemical studies indicate $(1,2,5)$.

Our findings agree with earlier biochemical studies of the 

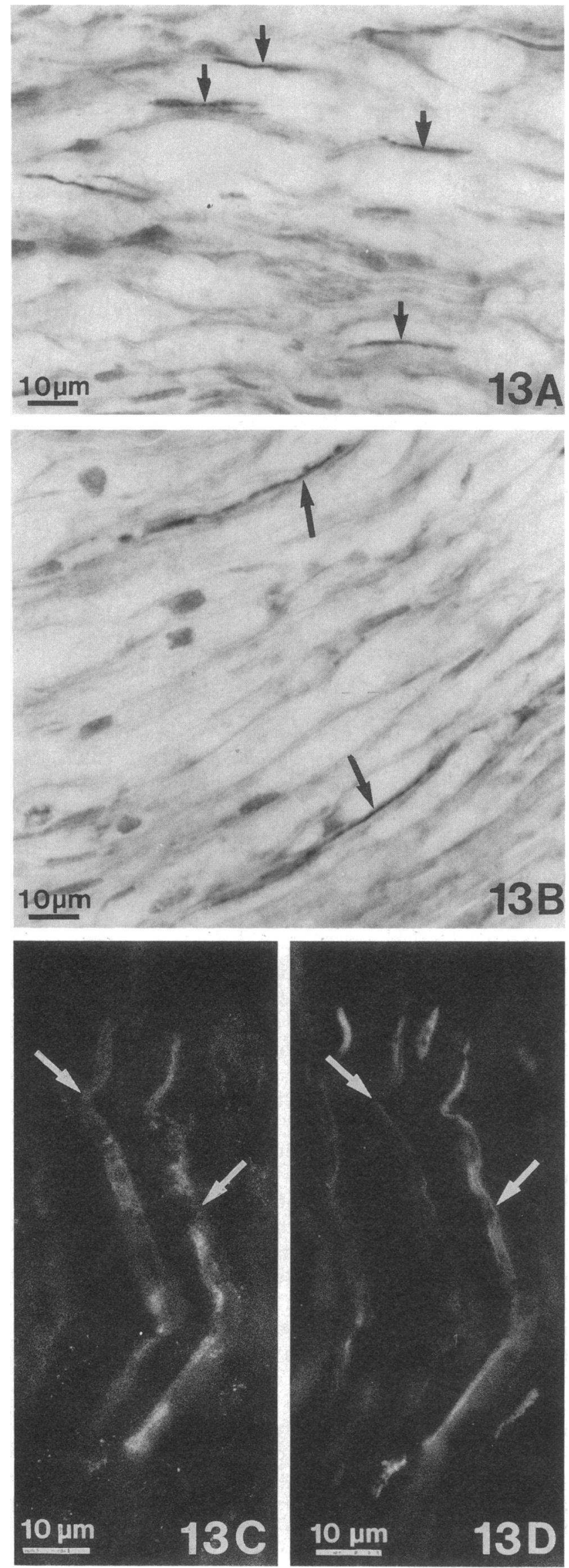

time course of apoE production in denervated sciatic nerves of the rat and rabbit $(1,2,5)$. Those studies showed that maximal apoE accumulation occurs during the third and fourth weeks and lags behind the maximal rate of apoE expression by about 2 wk. In addition, our study now demonstrates that apoA-I, the major protein of plasma HDL, also accumulates in the nerve during regeneration.

Previous studies have shown that the cholesterol used for remyelination in regenerating nerves originates both from degenerated myelin and from plasma (12-14). Our data provide evidence for a mechanism of cholesterol transfer and suggest that plasma HDL, particles rich in apoA-I, may provide the nerve with cholesterol from the plasma. $30-40 \%$ of the mass of rat HDL particles is cholesterol (51). (In the rat, most of the plasma cholesterol is carried in the HDL fraction, whereas in many other animals, including humans, most plasma cholesterol is transported by apoB-containing LDL. In these animals, therefore, it is possible that LDL may contribute cholesterol to regenerating nerves.) In addition, the apoA-I of the HDL, together with apoE, may provide a means of transporting cholesterol between cells within the nerve. The HDL particle has been shown to promote cholesterol efflux from cholesterolloaded cells in vitro $(8,9)$. These $\mathrm{HDL}$ acquire apoE along with cholesterol and lose apoA-I $(10,11)$. Such cholesterol-rich apoE-containing lipoproteins bind with high affinity to the LDL receptor $(6,7,11)$. Thus, the regenerating nerve contains the components necessary for transferring cholesterol stored in macrophages and neurolemmal fibroblasts during myelin breakdown back to Schwann cells displaying the LDL receptor during remyelination. The same mechanism may be active in the early stages of myelin breakdown, when Schwann cells are cholesterol-loaded: apoE and apoA-I may transfer cholesterol from the Schwann cell to the macrophage for storage or to the growing axon. The low level of apoE production by macrophages in the normal nerve and the expression of LDL receptors on many nerve cells would seem to indicate that apoE is involved in cholesterol transport within this tissue at all times. It may be that injury and repair only modulate the activity of this system.

The additional information on lipids provided by our morphologic and morphometric analysis of the regenerating nerve complements results from previous biochemical studies (39). Cholesteryl esters are most abundant in the nerve during the second week after injury and decline in the fourth week (39). Our data now show that these cholesteryl esters are depleted first in Schwann cells and then in macrophages and neurolemmal fibroblasts. Previous lipid analyses had shown that much of the free cholesterol originally in degenerating myelin is never stored as cholesteryl esters; high levels of free cholesterol persist in the injured nerve (39). Our study demonstrates that myelin degradation is completed as new myelin

Figure 13. Micrographs of distal rat sciatic nerves fixed $7 \mathrm{~d}$ after a crush injury and processed to detect LDL receptor. $(A$ and $B)$ As shown in this oblique $(A)$ and more longitudinal section $(B)$, dark peroxidase reaction product identifies LDL receptors in fibers at the periphery of some Schwann cell bundles (arrows). The nuclei of these sections have been stained. ( $C$ and $D$ ) This section was processed with dual fluorescence labeling to detect both LDL receptor $(C)$ and $160-\mathrm{kD}$ neurofilament protein $(D)$. Fibers (arrows) containing both are identified, as are fibers containing only one of these antigens. $(A$ and $B) \times 760 ;(C$ and $D) \times 625$. 

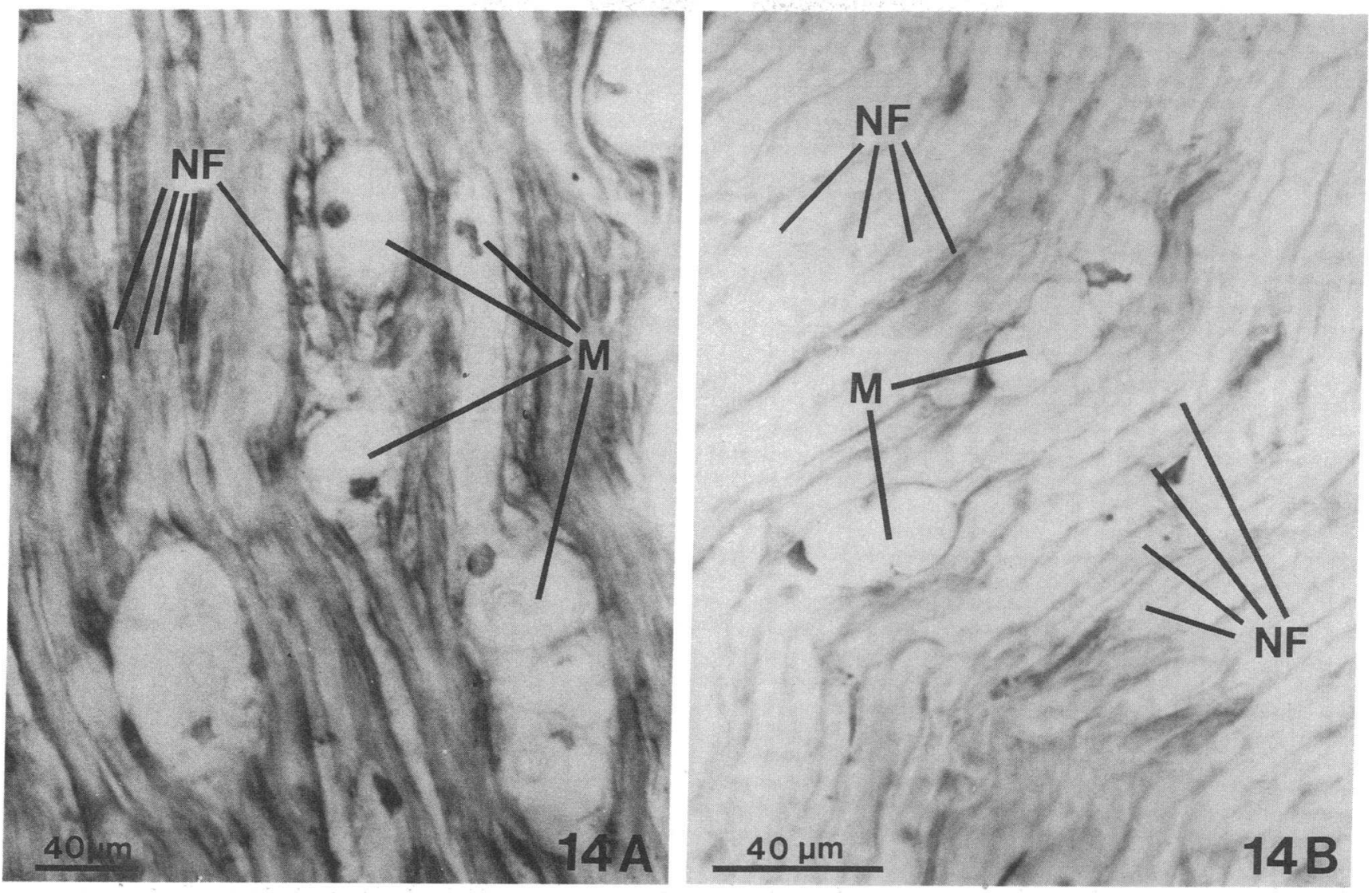

Figure 14. Micrographs of cryostat sections of distal rat sciatic nerves fixed $21 \mathrm{~d}(A)$ and $105 \mathrm{~d}(15 \mathrm{wk})(B)$ after a crush injury. Both sections were processed to detect LDL receptors. Cell nuclei have been counterstained in both of these sections. $(A)$ Dark peroxidase reaction product shows that LDL receptors are present at $21 \mathrm{~d}$ along the Schwann cell membranes at the surface of the nerve fibers $(N F)$. $(M)$ Macrophages. $(B)$ Dark peroxidase reaction product is barely detectable along the Schwann cell membranes at the surface of the nerve fibers $(N F)$ by $105 \mathrm{~d}$. The few lipid-loaded macrophages $(M)$ still present are now faintly outlined by peroxidase reaction product, indicating the presence of LDL receptors on their surfaces. $(A) \times 340 ;(B) \times 540$.

forms. In addition, most of the lysosomes found in Schwann cells during the fourth week are in cells that are not in contact with an axon. These results suggest that the partially degraded myelin present in lysosomes may represent an additional cholesterol store within the regenerating nerve.

Lipid degradation by macrophages in the nerve appears largely related to their clearance of lipoproteins and membrane debris from the extracellular matrix. Four weeks after injury, lipid-filled endosomes or lysosomes make up over $60 \%$ of the macrophage cellular volume (Table I). This is $2 \mathrm{wk}$ after almost all the original myelin has been degraded by Schwann cells (Table I). This degradation of lipid by macrophages could explain the high free fatty acid level detectable in the nerve at this time (39). The morphologic and immunocytochemical results also suggest that macrophages take up lipoproteins and other material from the extracellular matrix even earlier. This uptake of lipoproteins, together with the clearance of myelin and other membrane debris, may account for the cholesterol loading of macrophages early in regeneration.

In summary, our data suggest that the rise and fall in apoE production, the accumulation of apoE and apoA-I, and the expression of LDL receptors in the denervated sciatic nerve during regeneration and remyelination are associated with lipid transport, and particularly cholesterol transport. The induction of apoE secretion is associated with myelin breakdown and cholesterol accumulation by macrophages. A decline in apoE secretion and the accumulation of apoE- and apoA-Icontaining cholesterol-rich lipoprotein particles within the regenerating nerve are concurrent with the depletion of Schwann cell cholesterol stores during remyelination and the unloading of cholesterol stores from macrophages. Apolipoproteins E and A-I are known to participate in the redistribution of lipid from cholesterol-enriched to cholesterol-deficient cells (6). It is likely, therefore, that the presence of apoE and apoA-I in the nerve and the concurrent expression of LDL receptors at the elongating tips of axons and on myelinating Schwann cells provide a mechanism for cholesterol transfer among macrophages, Schwann cells, plasma, and axons. The presence of this transport system, coupled with the conservation of cholesterol within the degenerating nerve, suggests that cholesterol is important for regeneration-a conclusion in keeping with the massive membrane biogenesis that occurs in the regenerating nerve. One can hypothesize that the rate of regeneration depends in part upon the efficiency of lipid transport from the local environment to the elongating axon and remyelinating Schwann cell. 
Table II. Summary of the Major Physiologic Changes Associated with Lipid Metabolism in the Regenerating Rat Sciatic Nerve

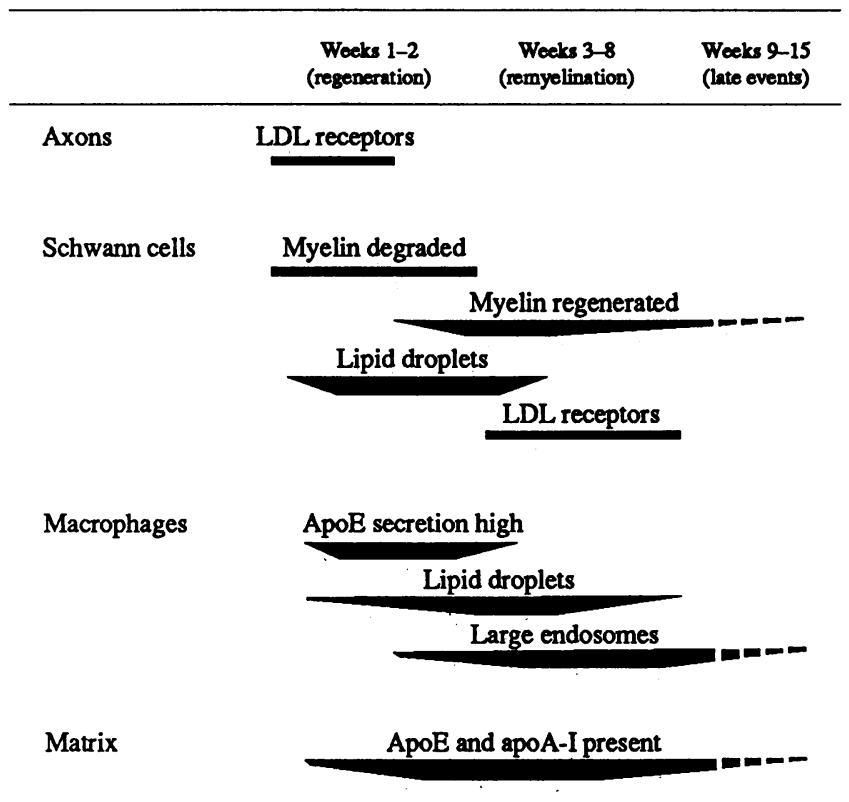

Increases and decreases in the thickness of a line are meant to indicate qualitative changes only. Dashed lines are present where no information is available as to the exact time point at which a feature is lost.

\section{Acknowledgments}

We thank Michele Prator for manuscript preparation, Al Averbach and Sally Gullatt Seehafer for editorial assistance, and James X. Warger and Charles Benedict for assistance with graphics.

Dr. Boyles and Dr. Hui are Established Investigators of the American Heart Association.

\section{References}

1. Müller, H. W., M. J. Ignatius, D. H. Hangen, and E. M. Shooter. 1986. Expression of specific sheath cell proteins during peripheral nerve growth and regeneration in mammals. J. Cell Biol. 102:393-402.

2. Skene, J. H. P., and E. M. Shooter. 1983. Denervated sheath cells secrete a new protein after nerve injury. Proc. Natl. Acad. Sci. USA. 80:4169-4173.

3. Ignatius, M. J., P. J. Gebicke-Härter, J. H. P. Skene, J. W. Schilling, K. H. Weisgraber, R. W. Mahley, and E. M. Shooter. 1986. Expression of apolipoprotein $\mathrm{E}$ during nerve degeneration and regeneration. Proc. Natl. Acad. Sci. USA. 83:1125-1129.

4. Snipes, G. J., C. B. McGuire, J. J. Norden, and J. A. Freeman. 1986. Nerve injury stimulates the secretion of apolipoprotein E by nonneuronal cells. Proc. Natl. Acad. Sci. USA. 83:1130-1134.

5. Müller, H. W., P. J. Gebicke-Härter, D. H. Hangen, and E. M. Shooter. 1985. A specific 37,000-dalton protein that accumulates in regenerating but not in nonregenerating mammalian nerves. Science (Wash. DC). 228:499-501.

6. Mahley, R. W. 1988. Apolipoprotein E: cholesterol transport protein with expanding role in cell biology. Science (Wash. DC). 240:622-630.

7. Mahley, R. W., T. L. Innerarity, S. C. Rall, Jr., and K. H. Weisgraber. 1984. Plasma lipoproteins: apolipoprotein structure and function. J. Lipid Res. 25:1277-1294.

8. Bates, S. R., and G. H. Rothblat. 1974. Regulation of cellular sterol flux and synthesis by human serum lipoproteins. Biochim. Biophys. Acta. 360:38-55.
9. Ho, Y. K., M. S. Brown, and J. L. Goldstein. 1980. Hydrolysis and excretion of cytoplasmic cholesteryl esters by macrophages: stimulation by high density lipoprotein and other agents. J. Lipid Res. 21:391-398.

10. Gordon, V., T. L. Innerarity, and R. W. Mahley. 1983. Formation of cholesterol- and apoprotein E-enriched high density lipoproteins in vitro. J. Biol. Chem. 258:6202-6212.

11. Koo, C., T. L. Innerarity, and R. W. Mahley. 1985. Obligatory role of cholesterol and apolipoprotein $\mathrm{E}$ in the formation of large cholesterol-enriched and receptor-active high density lipoproteins. $J$. Biol. Chem. 260:11934-11943.

12. Rawlins, F. A., E. T. Hedley-Whyte, G. Villegas, and B. G. Uzman. 1970. Reutilization of cholesterol-1,2- $\mathrm{H}^{3}$ in the regeneration of peripheral nerve. An autoradiographic study. Lab. Invest. 22:237240.

13. Rawlins, F. A., G. M. Villegas, E. T. Hedley-Whyte, and B. G. Uzman. 1972. Fine structural localization of cholesterol-1,2- $\mathrm{H}^{3}$ in degenerating and regenerating mouse sciatic nerve. J. Cell Biol. 52:615625.

14. Simon, G. 1966. Cholesterol ester in degenerating nerve: origin of cholesterol moiety. Lipids. 1:369-370.

15. Boyles, J., R. E. Pitas, E. Wilson, R. W. Mahley, and J. M. Taylor. 1985. Apolipoprotein E associated with astrocytic glia of the central nervous system and with nonmyelinating glia of the peripheral nervous system. J. Clin. Invest. 76:1501-1513.

16. Pitas, R. E., J. K. Boyles, S. H. Lee, D. Foss, and R. W. Mahley. 1987a. Astrocytes synthesize apolipoprotein $E$ and metabolize apolipoprotein E containing lipoproteins. Biochim. Biophys. Acta. 917:148-161.

17. Boyles, J. 1984. The use of mordants and osmium to stain lipids. EMSA Bull. 14:73-76.

18. De Bruijn, W. C., and P. Den Breejen. 1975. Glycogen, its chemistry and morphological appearance in the electron microscope. II. The complex formed in the selective contrast staining of glycogen. Histochem. J. 7:205-229.

19. Vermeer, B. J., W. C. De Bruijn, C. M. Van Gent, and C. P. M. De Winter. 1978. Ultrastructural findings on lipoproteins in vitro and in xanthomatous tissue. Histochem. J. 10:299-307.

20. Weibel, E. R., G. S. Kistler, and W. F. Scherle. 1966. Practical stereological methods for morphometric cytology. J. Cell Biol. 30:2338.

21. Weisgraber, K. H., S. C. Rall, Jr., and R. W. Mahley. 1981. Human $\mathrm{E}$ apoprotein heterogeneity. Cysteine-arginine interchanges in the amino acid sequence of the apo-E isoforms. J. Biol. Chem. 256:9077-9083.

22. Weisgraber, K. H., S. C. Rall, Jr., T. P. Bersot, R. W. Mahley, G. Franceschini, and C. R. Sirtori. 1983. Apolipoprotein A-I Milano $_{\text {- }}$ Detection of normal A-I in affected subjects and evidence for a cysteine for arginine substitution in the variant A-I. J. Biol. Chem. 258:25082513.

23. Weisgraber, K. H., Y. Newhouse, J. Seymour, S. C. Rall, Jr., and R. W. Mahley. 1985. Preparative Immobiline isoelectric focusing of plasma apolipoproteins on vertical slab gels. Anal. Biochem. 151:455-461.

24. Schneider, W. J., J. L. Goldstein, and M. S. Brown. 1985. Purification of the LDL receptor. Methods Enzymol. 109:405-417.

25. Towbin, H., T. Staehelin, and J. Gordon. 1979. Electrophoretic transfer of proteins from polyacrylamide gels to nitrocellulose sheets: procedure and some applications. Proc. Natl. Acad. Sci. USA. 76:4350-4354.

26. Kovanen, P. T., M. S. Brown, and J. L. Goldstein. 1979. Increased binding of low density lipoprotein to liver membranes from rats treated with $17 \alpha$-ethinyl estradiol. J. Biol. Chem. 254:1136711373.

27. Windler, E. E. T., P. T. Kovanen, Y.-S. Chao, M. S. Brown, R. J. Havel, and J. L. Goldstein. 1980. The estradiol-stimulated lipoprotein receptor of rat liver. A binding site that mediates the uptake of 
rat lipoproteins containing apoproteins B and E. J. Biol. Chem. 255:10464-10471.

28. Laemmli, U. K. 1970. Cleavage of structural proteins during the assembly of the head of bacteriophage T4. Nature (Lond.). 227:680-685.

29. Hui, D. Y., W. J. Brecht, E. H. Hall, G. Friedman, T. L. Innerarity, and R. W. Mahley. 1986. Isolation and characterization of apolipoprotein $\mathrm{E}$ receptor from canine and human liver. J. Biol. Chem. 261:4256-4267.

30. Mahley, R. M., T. L. Innerarity, K. H. Weisgraber, and D. L. Fry. 1977. Canine hyperlipoproteinemia and atherosclerosis: accumulation of lipid by aortic medial cells in vivo and in vitro. Am. J. Pathol. 87:205-226.

31. Hunkapiller, M. W., E. Lujan, F. Ostrander, and L. E. Hood. 1983. Isolation of microgram quantities of proteins from polyacrylamide gels for amino acid sequence analysis. Methods Enzymol. 91:227-236.

32. Hoff, H. F., and R. E. Morton. 1985. Lipoproteins containing apo-E extracted from human aortas: structure and function. Ann. N. Y. Acad. Sci. 454:183-194.

33. Pitas, R. E., J. K. Boyles, S. H. Lee, D. Y. Hui, and K. H. Weisgraber. 1987. Lipoproteins and their receptors in the central nervous system: characterization of the lipoproteins in cerebrospinal fluid and identification of apolipoprotein B, E (low density lipoprotein) receptors in the brain. J. Biol. Chem. 262:14352-14360.

34. Mellick, R. S., and J. B. Cavanagh. 1968. Changes in blood vessel permeability during degeneration and regeneration in peripheral nerves. Brain. 91:141-160.

35. Olsson, Y. 1966. Studies of vascular permeability in peripheral nerves. I. Distribution of circulating fluorescent serum albumin in normal, crushed and sectioned rat sciatic nerve. Acta Neuropathol. 7:1-15.

36. Belin, J., and A. D. Smith. 1976. Wallerian degeneration of rat sciatic nerve. Changes in cholesteryl ester content and fatty acid composition. J. Neurochem. 27:969-970.

37. Berry, J. F., W. H. Cevallos, and R. R. Wade, Jr. 1965. Lipid class and fatty acid composition of intact peripheral nerve and during Wallerian degeneration. J. Am. Oil Chem. Soc. 42:492-500.

38. Wood, J. G., and R. M. C. Dawson. 1974. Lipid and protein changes in sciatic nerve during Wallerian degeneration. J. Neurochem. 22:631-635.

39. Yao, J. K., V. Natarajan, and P. J. Dyck. 1980. The sequential alterations of endoneurial cholesterol and fatty acid in Wallerian degeneration and regeneration. J. Neurochem. 35:933-940.

40. Cajal, S. R. Y. 1928. Degeneration and Regeneration of the Nervous System. R. M. May, editor. Oxford University Press, London. 224-264.

41. Guth, L. 1956. Regeneration in the mammalian peripheral nervous system. Physiol. Rev. 36:441-478.

42. Innerarity, T. L., R. E. Pitas, and R. W. Mahley. 1979. Binding of arginine-rich (E) apoprotein after recombination with phospholipid vesicles to the low density lipoprotein receptors of fibroblasts. J. Biol. Chem. 254:4186-4190.

43. Cardin, A. D., M. Hirose, D. T. Blankenship, R. L. Jackson, and J. A. K. Harmony. 1986. Binding of a high reactive heparin to human apolipoprotein E: identification of two heparin-binding domains. Biochem. Biophys. Res. Commun. 134:783-789.

44. Weisgraber, K. H., S. C. Rall, Jr., R. W. Mahley, R. W. Milne, Y. L. Marcel, and J. T. Sparrow. 1986. Human apolipoprotein E: determination of the heparin binding sites of apolipoprotein E3. $J$. Biol. Chem. 261:2068-2076.

45. Ignatius, M. J., E. M. Shooter, R. E. Pitas, and R. W. Mahley. 1987. Lipoprotein uptake by neuronal growth cones in vitro. Science (Wash. DC). 236:959-962.

46. Williams, P. L., and S. M. Hall. 1971. Chronic Wallerian degeneration-an in vivo and ultrastructural study. J. Anat. 109:487503.

47. Basu, S. K., M. S. Brown, Y. K. Ho, R. J. Havel, and J. L. Goldstein. 1981. Mouse macrophages synthesize and secrete a protein resembling apolipoprotein E. Proc. Natl. Acad. Sci. USA. 78:75457549.

48. Basu, S. K., Y. K. Ho, M. S. Brown, D. W. Bilheimer, R. G. W. Anderson, and J. L. Goldstein. 1982. Biochemical and genetic studies of the apoprotein E secreted by mouse macrophages and human monocytes. J. Biol. Chem. 257:9788-9795.

49. Werb, Z., and J. R. Chin. 1983. Apoprotein E is synthesized and secreted by resident and thioglycollate-elicited macrophages but not by pyran copolymer- or bacillus Calmette-Guerin-activated macrophages. J. Exp. Med. 158:1272-1293.

50. Werb, Z., and J. R. Chin. 1983. Onset of apoprotein E secretion during differentiation of mouse bone marrow-derived mononuclear phagocytes. J. Cell Biol. 97:1113-1118.

51. Weisgraber, K. H., and R. W. Mahley. 1983. Characterization of rat plasma lipoproteins. In CRC Handbook of Electrophoresis, Vol. IV: Lipoprotein Studies of Nonhuman Species. L. A. Lewis and H. K. Naito, editors. CRC Press, Boca Raton, FL. 103-132. 